\title{
EARLINET instrument intercomparison campaigns: overview on strategy and results
}

Ulla Wandinger ${ }^{1}$, Volker Freudenthaler ${ }^{2}$, Holger Baars $^{1}$, Aldo Amodeo ${ }^{3}$, Ronny Engelmann ${ }^{1}$, Ina Mattis ${ }^{1, \text { a }}$, Silke Groß $^{2, b}$, Gelsomina Pappalardo ${ }^{3}$, Aldo Giunta ${ }^{3}$, Giuseppe D’Amico ${ }^{3}$, Anatoli Chaikovsky ${ }^{4}$, Fiodor Osipenko ${ }^{4}$, Alexander Slesar ${ }^{4}$, Doina Nicolae ${ }^{5}$, Livio Belegante ${ }^{5}$, Camelia Talianu ${ }^{5}$, Ilya Serikov ${ }^{6}$ Holger Linné $^{6}$, Friedhelm Jansen ${ }^{6}$, Arnoud Apituley ${ }^{7}$, Keith M. Wilson ${ }^{7}$, Martin de Graaf ${ }^{7, c}$, Thomas Trickl ${ }^{8}$, Helmut Giehl ${ }^{8}$, Mariana Adam ${ }^{9, d}$, Adolfo Comerón ${ }^{10}$, Constantino Muñoz-Porcar ${ }^{10}$, Francesc Rocadenbosch ${ }^{10}$, Michaël Sicard ${ }^{10}$, Sergio Tomás $^{10, e}$, Diego Lange ${ }^{10, f}$, Dhiraj Kumar ${ }^{10, g}$, Manuel Pujadas ${ }^{11}$, Francisco Molero ${ }^{11}$, Alfonso J. Fernández ${ }^{11}$, Lucas Alados-Arboledas ${ }^{12,13}$, Juan Antonio Bravo-Aranda ${ }^{12,13}$, Francisco Navas-Guzmán ${ }^{12,13, h}$, Juan Luis Guerrero-Rascado ${ }^{12,13,14}$, María José Granados-Muñoz ${ }^{12,13, i}$, Jana Preißler ${ }^{14, j}$ Frank Wagner $^{14,21}$, Michael Gausa ${ }^{15}$, Ivan Grigorov ${ }^{16}$, Dimitar Stoyanov ${ }^{16}$, Marco Iarlori ${ }^{17}$, Vincenco Rizi ${ }^{17}$, Nicola Spinelli ${ }^{18,19}$, Antonella Boselli ${ }^{19,3}$, Xuan Wang ${ }^{19,20}$, Teresa Lo Feudo ${ }^{18,19, k}$, Maria Rita Perrone ${ }^{21}$ Ferdinando De Tomasi $^{21}$, and Pasquale Burlizzi ${ }^{21}$

${ }^{1}$ Leibniz Institute for Tropospheric Research, Permoserstr. 15, 04318 Leipzig, Germany

${ }^{2}$ Ludwig-Maximilians-Universität, Meteorological Institute, Munich, Germany

${ }^{3}$ Consiglio Nazionale delle Ricerche, Istituto di Metodologie per l'Analisi Ambientale,

Potenza, Italy

${ }^{4}$ B.I. Stepanov Institute of Physics, National Academy of Sciences of Belarus, Minsk, Belarus

${ }^{5}$ National Institute of Research and Development for Optoelectronics, Magurele, Ilfov, Romania

${ }^{6}$ Max Planck Institute for Meteorology, Hamburg, Germany

${ }^{7}$ Royal Netherlands Meteorological Institute, De Bilt, the Netherlands

${ }^{8}$ Institut für Meteorologie und Klimaforschung-Atmosphärische Umweltforschung, Karlsruhe Institute of

Technology, Garmisch-Partenkirchen, Germany

${ }^{9}$ European Commission, Joint Research Centre, Institute for Environment and

Sustainability, Ispra, Italy

${ }^{10}$ Universitat Politècnica de Catalunya, Barcelona, Spain

${ }^{11}$ Centro de Investigaciones Energéticas, Medioambientales y Tecnológicas, Department of Environment, Madrid, Spain

${ }^{12}$ Department of Applied Physics, Faculty of Sciences, University of Granada, Granada, Spain

${ }^{13}$ Andalusian Institute for Earth System Research, Granada, Spain

${ }^{14}$ Universidade de Évora, Centro de Geofísica de Évora, Évora, Portugal

${ }^{15}$ Alomar, Andøya Rocket Range, Andøya, Norway

${ }^{16}$ Institute of Electronics, Bulgarian Academy of Sciences, Sofia, Bulgaria

${ }^{17}$ Università degli Studi dell' Aquila, CETEMPS/DSFC, L'Aquila, Italy

${ }^{18}$ Dipartimento di Fisica Università Federico II di Napoli, Naples, Italy

${ }^{19}$ Consorzio Nazionale Interuniversitario per le Scienze Fisiche della Materia, Naples, Italy

${ }^{20}$ Consiglio Nazionale delle Ricerche, Istituto superconduttori, materiali innovativi e dispositivi, Naples, Italy

${ }^{21}$ Università del Salento, Dipartimento di Matematica e Fisica, Lecce, Italy

anow at: Meteorological Observatory Hohenpeißenberg, Deutscher Wetterdienst, Hohenpeißenberg, Germany

${ }^{b}$ now at: Deutsches Zentrum für Luft- und Raumfahrt, Institute of Atmospheric Physics, Oberpfaffenhofen, Germany

${ }^{c}$ now at: Faculty of Civil Engineering and Geosciences, Delft University of Technology, Delft, the Netherlands 
${ }^{\mathrm{d}}$ now at: Met Office, Exeter, UK

${ }^{\mathrm{e}}$ now at: Institut d'Estudis Espacials de Catalunya, Barcelona, Spain

f now at: Universidad Católica Boliviana San Pablo, Cochabamba, Bolivia

gnow at: Universidad Carlos III de Madrid, Madrid, Spain

${ }^{h}$ now at: Institute of Applied Physics, University of Bern, Bern, Switzerland

${ }^{i}$ now at: Table Mountain Facility, Jet Propulsion Laboratory, Wrightwood, USA

${ }^{j}$ now at: Centre for Climate and Air Pollution Studies, School of Physics, National University of Ireland, Galway, Ireland

know at: Consiglio Nazionale delle Ricerche, Istituto di Scienze dell' Atmosfera e del Clima, UOS of Lamezia Terme, Italy

Correspondence to: Ulla Wandinger (ulla@tropos.de)

Received: 15 September 2015 - Published in Atmos. Meas. Tech. Discuss.: 9 October 2015

Revised: 12 February 2016 - Accepted: 15 February 2016 - Published: 10 March 2016

\begin{abstract}
This paper introduces the recent European Aerosol Research Lidar Network (EARLINET) quality-assurance efforts at instrument level. Within two dedicated campaigns and five single-site intercomparison activities, 21 EARLINET systems from 18 EARLINET stations were intercompared between 2009 and 2013. A comprehensive strategy for campaign setup and data evaluation has been established. Eleven systems from nine EARLINET stations participated in the EARLINET Lidar Intercomparison 2009 (EARLI09). In this campaign, three reference systems were qualified which served as traveling standards thereafter. EARLINET systems from nine other stations have been compared against these reference systems since 2009. We present and discuss comparisons at signal and at product level from all campaigns for more than 100 individual measurement channels at the wavelengths of $355,387,532$, and $607 \mathrm{~nm}$. It is shown that in most cases, a very good agreement of the compared systems with the respective reference is obtained. Mean signal deviations in predefined height ranges are typically below $\pm 2 \%$. Particle backscatter and extinction coefficients agree within $\pm 2 \times 10^{-4} \mathrm{~km}^{-1} \mathrm{sr}^{-1}$ and $\pm 0.01 \mathrm{~km}^{-1}$, respectively, in most cases. For systems or channels that showed larger discrepancies, an in-depth analysis of deficiencies was performed and technical solutions and upgrades were proposed and realized. The intercomparisons have reinforced confidence in the EARLINET data quality and allowed us to draw conclusions on necessary system improvements for some instruments and to identify major challenges that need to be tackled in the future.
\end{abstract}

\section{Introduction}

The European Aerosol Research Lidar Network (EARLINET) was founded in the year 2000 with the major goal to establish an aerosol climatology for Europe (Pappalardo et al., 2014). The network has been continuously growing and currently consists of 27 stations with about 35 individual lidar systems distributed over 16 European countries. Although all systems are specifically designed for aerosol observations in the troposphere and, partly, the stratosphere, the network comprises a large variety of individual technical solutions from small laboratory-based systems to mediumsized portable lidars and large container-based instruments. Moreover, technical improvements, resulting to a large extent from exchange of expertise within the network, lead to continuous alterations of the setups. Because of this diversity, the need for a rigorous quality-assurance (QA) program was very clear right from the start of the EARLINET initiative. Consequently, great effort was put into QA activities at the instrument and algorithm levels over the years.

In the first phase of EARLINET from 2000 to 2003, when EARLINET was implemented as a research project supported by the European Commission under the Fifth Framework Programme, QA activities were focussed on intercomparisons of lidar systems (Matthias et al., 2004) and of dataevaluation algorithms (Böckmann et al., 2004; Pappalardo et al., 2004). In order to check the quality of the instruments within the network, an intercomparison strategy was developed based on the application of reference lidar systems that can serve as traveling standards (Matthias et al., 2004). All 19 EARLINET systems, which were part of the network at that time, had been intercompared, some in dedicated campaigns, but most of them pairwise by comparison with the mobile reference systems from the EARLINET stations in Hamburg and Munich. Comparisons were exclusively performed for the products provided to the EARLINET database, i.e., profiles of particle backscatter and extinction coefficients (Matthias et al., 2004). As a general result, it was found that typical mean deviations of particle backscatter coefficients were $10 \%$ in the planetary boundary layer (PBL) and $1 \times 10^{-4} \mathrm{~km}^{-1} \mathrm{sr}^{-1}$ in the free troposphere and thus well below the thresholds of $25 \%$ and $5 \times 10^{-4} \mathrm{~km}^{-1} \mathrm{sr}^{-1}$, respectively, representing the predefined quality criteria. Only few 
comparisons were made for particle extinction coefficients, but mean deviations were also small in these cases with values of less than $5 \%$ or $0.01 \mathrm{~km}^{-1}$.

During EARLINET-ASOS (Advanced Sustainable Observation System), an Integrated Activity within the Sixth Framework Programme from 2006 to 2011, QA activities were intensified and included also the development of tools for internal tests of accuracy and temporal stability of individual lidar systems at any time, i.e., independent of dedicated intercomparisons with reference instruments (Freudenthaler et al., 2016). The QA activities have been continued in the framework of ACTRIS (Aerosols, Clouds, and Trace gases Research InfraStructure; funded as Integrated Infrastructure Initiative in the Seventh Framework Programme and as Integrating Activity in Horizon 2020), part of which EARLINET has been since April 2011.

In this paper, we report on instrument intercomparison campaigns performed within EARLINET-ASOS and ACTRIS from 2009 to 2013. Focus of the activities was on the development and test of new reference systems, the integration of new EARLINET stations, and the test of new or considerably enhanced instruments at initial EARLINET stations. It should be noted that in the period from 2000 to 2003 the major goal of EARLINET was to provide independent measurements of particle extinction and backscatter coefficients by applying the Raman lidar method at least at one wavelength, preferably in the UV. Since then, a large number of EARLINET instruments have been upgraded to so-called $3+2$ Raman lidar systems. The term $3+2$ stands for the independent measurement of three backscatter coefficients (at 355, 532, and $1064 \mathrm{~nm}$ ) and two extinction coefficients (at 355 and $532 \mathrm{~nm}$ ) by the use of an Nd:YAG laser with frequency doubling and tripling and the detection of elastic-backscatter signals at the three laser wavelengths and of vibration-rotation or pure rotational Raman signals of a reference gas (nitrogen and/or oxygen) at the two shorter wavelengths. With this measurement capability it is possible to retrieve not only optical but also microphysical particle properties (e.g., Müller et al., 1999; Veselovskii et al., 2002; Böckmann et al., 2005; Müller et al., 2015). In the first EARLINET period, 11 out of the 19 EARLINET stations delivered extinction and backscatter coefficients in the UV, but only two of them were $3+2$ systems (Matthias et al., 2004). Currently (in 2015), there are $223+2$ systems at 18 EARLINET stations, and their number is steadily growing. Many systems have polarization measurement capabilities in addition, i.e., the particle linear depolarization ratio is measured at least at one wavelength (Freudenthaler et al., 2009; Belegante et al., 2016; Bravo-Aranda et al., 2016). This quantity contains information about the presence of large, nonspherical particles and is an indispensable parameter for aerosol typing, in particular for the identification of mineral dust in the atmosphere.

The increased number and complexity of lidar systems within the network requires also an improved QA strategy.
The major challenge of the QA efforts lies in the fact that absolute calibration techniques for aerosol lidar systems do not exist and that it is practically impossible to validate aerosol lidar products by comparison with independent measurements externally, e.g., from balloon-borne in situ observations as it is done in the case of water-vapor or ozone lidars (e.g., Leblanc et al., 2011; Nair et al., 2012). Thus, the direct intercomparison of collocated instruments is the only objective and commonly accepted way to assess the overall performance of individual aerosol lidars. The general goal of such an intercomparison is to identify principal deficiencies, which may lead to systematic errors of the aerosol lidar products or unreliable results in specific parts of the profile. For instance, in the near range, lidar systems may suffer from electronic saturation effects, uncertain optical overlap functions, and nonlinear signal distortions. In the far range, the limited dynamic range of data acquisition, together with electronic signal perturbance, may hinder appropriate background substraction and Rayleigh calibration. Also, principal optical misalignments or even system design errors may be discovered. Therefore, a two-step intercomparison strategy is now applied for EARLINET, starting with a comparison at signal level to detect the validity range and the uncertainties of each individual signal part, followed by the comparison of aerosol products derived from (partly combined) lidar profiles.

In order to cover the larger number of network stations and to become more flexible with the intercomparison strategy, it was decided within EARLINET-ASOS to define several mobile systems as reference lidars. Two $3+2$ systems with polarization capability have been newly developed for this purpose by the EARLINET groups in Hamburg and Potenza. It was envisaged to perform, in a first step, a specific intercomparison campaign for the two new and three previously existing mobile reference systems (from Munich, Maisach, and Minsk), and to travel with these systems to other EARLINET stations for single-site intercomparisons afterwards. Fortunate circumstances made it possible that not only the reference lidars but eleven EARLINET systems from nine stations participated already in the first campaign, the EARLINET Lidar Intercomparison 2009 (EARLI09) in Leipzig, Germany, in May 2009. Four more systems could be validated by comparison with one of the reference systems in a second campaign, the Spanish Lidar Intercomparison 2010 (SPALI10), which took place at Madrid, Spain, in October and November 2010. Finally, single-site intercomparisons were realized at five EARLINET stations with six lidar systems between 2009 and 2013. The strategies developed and applied in these campaigns and their results are discussed in the following. In Sect. 2 an overview of the campaigns and a description of the involved systems is given. The measurement and data-processing strategies are outlined in Sect. 3. Results are discussed based on the comparisons at signal and at product levels in Sect. 4. Further discussion of the findings is provided in Sect. 5. Finally, Sect. 6 summa- 
rizes the conclusions and gives an outlook on future activities.

\section{Instrument intercomparison campaigns}

\subsection{Overview}

Figure 1 gives an overview on the stations involved in the EARLINET intercomparison campaigns between 2009 and 2013. Mobile lidars from the EARLINET stations in Hamburg, Potenza, Munich, Maisach, Bucharest, Cabauw, Minsk, Ispra, and Garmisch-Partenkirchen were moved to Leipzig and intercompared during EARLI09 in May 2009, together with a stationary and a mobile system of the Leipzig site. Afterwards, the reference lidar from Hamburg was brought to the EARLINET station at Andenes, Norway, for a single-site intercomparison in October/November 2009. The Munich system traveled to Sofia to intercompare two lidars at this site in October 2010. In October/November 2010, the reference lidar from Potenza participated in the SPALI10 campaign in Madrid, where the intercomparison of the systems from the stations in Évora, Barcelona, Granada, and Madrid took place. The L'Aquila lidar was intercompared with the Munich reference system in September 2012. Finally, in October 2013, the Potenza reference lidar was moved to Naples and Lecce for single-site intercomparisons.

In the following, we introduce the individual campaigns and the participating instruments in more detail. Table 1 lists the involved lidar systems by name and institution. Their measurement channels are detailed in Table 2. The lidar ID used here includes the ID of the EARLINET station to which the instrument belongs (two letters) and a number in order to distinguish systems from stations with more than one instrument.

\subsection{EARLI09-EARLINET Lidar Intercomparison 2009}

EARLI09 took place at the Leibniz Institute for Tropospheric Research (TROPOS) in Leipzig, Germany, between 4 and 31 May 2009. As mentioned, this campaign was planned to compare the reference lidar systems, but several other partners took the opportunity to join, and finally 11 EARLINET lidar systems were collocated. In this way, the campaign became the largest lidar intercomparison performed so far, with challenging logistical requirements. Three container-based systems, one van, two trailers, and three stand-alone systems were placed next to the stationary Leipzig EARLINET lidar, around and on top of the institute's building, and supplied with more than $120 \mathrm{~kW}$ of electrical power and internet connection. The campaign also served for the implementation and test of the new EARLINET intercomparison strategy (see Sect. 3 for details). Thus, the first week of the campaign was scheduled for preparations of hardware and software. Between 11 and 28 May, 20 measure-

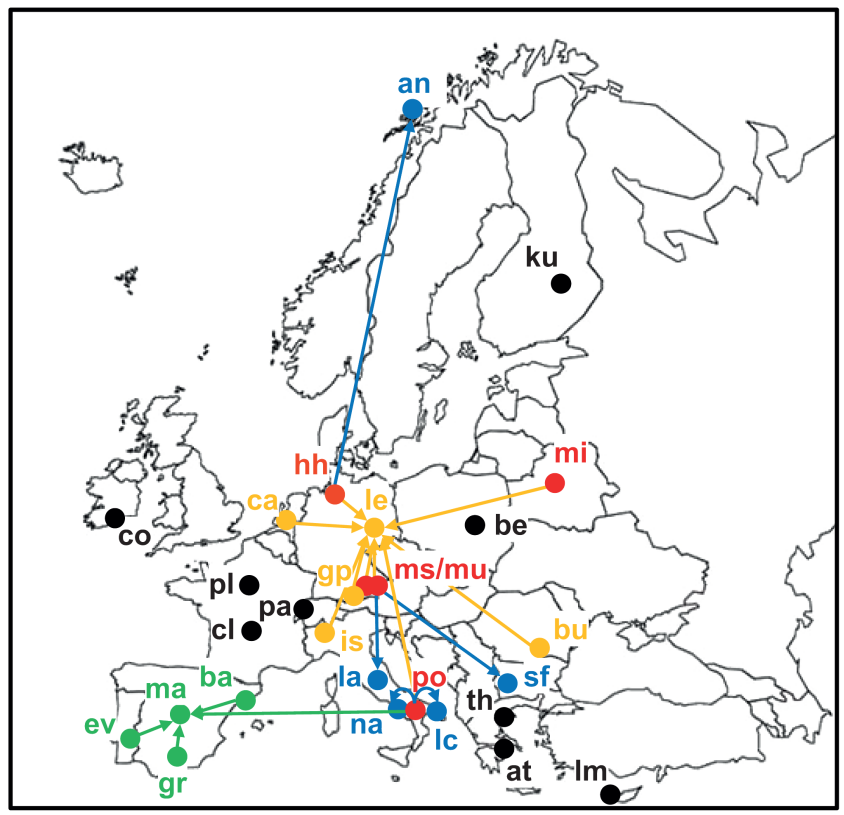

Figure 1. Map of EARLINET and stations involved in the intercomparison campaigns (station IDs: an - Andenes, at - Athens, ba Barcelona, be - Belsk, bu - Bucharest, ca - Cabauw, cl - ClermontFerrand, co - Cork, ev - Évora, gp - Garmisch-Partenkirchen, gr - Granada, hh - Hamburg, is - Ispra, ku - Kuopio, la - L'Aquila, lc - Lecce, le - Leipzig, lm - Limassol, ma - Madrid, ms/mu Maisach/Munich, mi - Minsk, na - Naples, pa - Payerne, pl Palaiseau, po - Potenza, sf - Sofia, th - Thessaloniki). Red colors show stations operating reference systems. Participation of instruments from stations in EARLI09 (yellow), SPALI10 (green), and single-site intercomparisons (blue) is indicated. Black dots represent stations which were not involved in the 2009-2013 intercomparisons.

ment sessions of $1-3 \mathrm{~h}$ duration on 11 days were performed. Radiosondes were launched for each session. Daily briefings, including an expert's weather forecast, served for the planning of the sessions and for the discussion of results from the previous day. The latter were obtained using a new dataevaluation concept (see Sect. 3) that allowed us to handle, on a daily basis, the signals from more than 100 lidar channels provided by the 11 lidar systems which are described in the following (see also Tables 1 and 2).

The Atmospheric Raman Lidar (ARL2-mobile, ID: hh01) of the Max Planck Institute for Meteorology (MPI-MET) in Hamburg is a multiwavelength Raman lidar. With 26 measurement channels (see Table 2) it is the most extensive EARLINET lidar. The emitter is a $440 \mathrm{~mJ}$ Nd:YAG laser (Quantel, Brilliant B). The system has two unique features. Firstly, it covers the altitude range from about $50 \mathrm{~m}$ above ground up to the stratosphere by applying three separate receivers, which are fiber-coupled to two Newtonian telescopes with diameters of 380 (far range) and $150 \mathrm{~mm}$ (near range) and a lens telescope with a diameter of $22 \mathrm{~mm}$ (lowest heights), re- 
Table 1. EARLINET systems participating in the intercomparison campaigns

\begin{tabular}{|c|c|}
\hline Lidar ID & Lidar name and institution \\
\hline \multicolumn{2}{|l|}{ EARLI09 } \\
\hline hh01 & ARL2-mobile, MPI-MET, Hamburg, Germany \\
\hline $\mathrm{ms} 01$ & MULIS, LMU Munich, Germany \\
\hline mu01 & POLIS, LMU Munich, Germany \\
\hline po01 & MUSA, CNR-IMAA, Potenza, Italy \\
\hline $\operatorname{mi01}$ & LMR-mobile, BISIP, Minsk, Belarus \\
\hline le01 & MARTHA, TROPOS, Leipzig, Germany \\
\hline le02 & Polly XT, TROPOS, Leipzig, Germany \\
\hline is01 & CAML, JRC, Ispra, Italy \\
\hline bu01 & RALI, INOE 2000, Bucharest, Romania \\
\hline gp01 & HSRL, IMK-IFU, Garmisch-Partenkirchen, Germany \\
\hline $\mathrm{ca} 01$ & CAELI, KNMI, De Bilt, the Netherlands \\
\hline \multicolumn{2}{|c|}{ SPALI10 (reference system: po01) } \\
\hline gr01 & Raymetrics LR331-D400, CEAMA, Universidad de Granada, Spain \\
\hline ev01 & PAOLI, Universidade de Évora, Portugal \\
\hline $\mathrm{ma01}$ & LIDAR-CIEMAT, CIEMAT, Madrid, Spain \\
\hline $\mathrm{ba} 02$ & UPC-MRL, UPC, Barcelona, Spain \\
\hline \multicolumn{2}{|c|}{ ALI09 (reference system: hh01) } \\
\hline an01 & Tropospheric Lidar, Alomar, Andøya Rocket Range, Norway \\
\hline \multicolumn{2}{|c|}{ SOLI10 (reference system: mu01, upgraded) } \\
\hline sf01 & Lidar with $\mathrm{CuBr}$ laser, IE-BAS, Sofia, Bulgaria \\
\hline sf02 & Lidar with Nd:YAG laser, IE-BAS, Sofia, Bulgaria \\
\hline \multicolumn{2}{|c|}{ LALI12 (reference system: mu01, upgraded) } \\
\hline la01 & UV lidar, Università degli Studi dell'Aquila, Italy \\
\hline \multicolumn{2}{|c|}{ NALI13 (reference system: po01) } \\
\hline na01 & MALIA, CNISM, Naples, Italy \\
\hline \multicolumn{2}{|c|}{ LELI13 (reference system: po01) } \\
\hline lc01 & UNILE lidar, Università del Salento, Lecce, Italy \\
\hline
\end{tabular}

spectively. Depolarization measurements at $532 \mathrm{~nm}$ are utilized with two detection channels, which are directly coupled to another $200 \mathrm{~mm}$ Newtonian telescope. The second remarkable feature of the system is its capability to detect rotational Raman signals at both 355 and $532 \mathrm{~nm}$ with a specific grating technique. In addition, the vibration-rotation signals at $387 \mathrm{~nm}$ (nitrogen) and $407 \mathrm{~nm}$ (water vapor) are measured. Rotational Raman signals serve for temperature measurements, but can also be used for extinction-coefficient retrievals. Signals are detected by Hamamatsu photomultiplier tubes (PMTs) in photon-counting detection mode in the UV and visible wavelength ranges and by Licel/EG\&G avalanche photodiodes (APDs) in analog detection mode at $1064 \mathrm{~nm}$.

The Meteorological Institute of the Ludwig-MaximiliansUniversität (LMU) in Munich participated with two instruments, which both had already served as reference systems in EARLINET. POLIS (Portable Lidar System, ID: mu01) is a small, rugged lidar system with an exchangeable detector unit. It applies a $50 \mathrm{~mJ}$ laser (Big Sky, Ultra GRM) and a $200 \mathrm{~mm}$ Dall-Kirkham Cassegrain telescope. During EARLI09 the instrument was operated as a twochannel $355 \mathrm{~nm}$ system, which detected either parallel- and cross-polarized elastic backscatter signals or the total elastic backscattering together with the $387 \mathrm{~nm}$ nitrogen Raman signal with Licel/Hamamatsu PMTs for combined analog and photon-counting detection (Freudenthaler et al., 2009). POLIS was upgraded to three channels in 2010 (see below) and to six channels in 2013 (Freudenthaler et al., 2015). The second system, MULIS (Multichannel Lidar System, ID: ms01), is a $3+2$ Raman lidar with polarization measurement capability at $532 \mathrm{~nm}$ (Freudenthaler et al., 2009). This lidar performs the EARLINET observations at the station of Maisach, near Munich. The instrument applies a 1.6 J Nd:YAG laser (Continuum, Surelite II) and a $300 \mathrm{~mm}$ Cassegrain telescope. Hamamatsu PMTs (UV and visible wavelength range) and a Licel/EG\&G APD (at $1064 \mathrm{~nm}$ ) are used as detectors. All elastic-backscatter signals are measured in analog detection mode. For Raman signals, the combined analog and photoncounting technique (Licel) is applied. MULIS was developed as a reference lidar for the first phase of EARLINET (2000-2003) and served as a prototype for MUSA (Multiwavelength System for Aerosol, ID: po01), the reference system of CNR-IMAA (Consiglio Nazionale delle RicercheIstituto di Metodologie per l'Analisi Ambientale) in Potenza. Thus, MUSA has very similar specifications as MULIS, with the exception that it applies the Licel combined analog and photon-counting detectors also for the elastic-backscatter signals at 355 and $532 \mathrm{~nm}$ (Madonna et al., 2011).

The fifth EARLINET reference system is the LMRmobile (Lidar Multiwavelength Raman, ID: mi01) of the B. I. Stepanov Institute of Physics (BISIP), Minsk, Belarus. It is a compact, scanning, stand-alone system, which applies a $250 \mathrm{~mJ}$ Nd:YAG laser (SOLAR TII, LF-114) and a $300 \mathrm{~mm}$ Cassegrain telescope. The system has six measurement channels in $3+2$ configuration with polarization discrimination at $532 \mathrm{~nm}$. Analog detection with PMTs $(355,532 \mathrm{~nm})$ and an APD $(1064 \mathrm{~nm})$ is applied for elastic-backscatter signals. Photon-counting PMTs are used for Raman signals (387, $607 \mathrm{~nm})$.

MARTHA (Multiwavelength Atmospheric Raman Lidar for Temperature, Humidity, and Aerosol Profiling, ID: le01) of TROPOS is the stationary EARLINET lidar at Leipzig, Germany. It works with a $1.6 \mathrm{~J} \mathrm{Nd:YAG} \mathrm{laser} \mathrm{(Spectra}$ Physics, Quanta-Ray PRO 290) and an $800 \mathrm{~mm}$ Cassegrain telescope. It allows $3+2$ Raman lidar observations and depolarization measurements at $532 \mathrm{~nm}$. In addition, the instrument has channels for rotational Raman observations at 355 (since 2011, not during EARLI09) and $532 \mathrm{~nm}$, water-vapor measurements, and dual-field-of-view observations (Mattis et al., 2004; Schmidt et al., 2013). PMTs in photon-counting mode are employed in all channels, including at $1064 \mathrm{~nm}$. For routine, automatic observations, the Polly ${ }^{\mathrm{XT}}$ lidar (Portable Aerosol Raman Lidar System, extended version, ID: le02) is applied in Leipzig as well. It has a $3+2$ Raman lidar setup, utilizing a $450 \mathrm{~mJ} \mathrm{Nd}$ :YAG laser (Continuum, Inlite III) and a $300 \mathrm{~mm}$ Newton telescope (Althausen et al., 2009). Hamamatsu photon-counting-only PMTs are deployed in all channels. Total and cross-polarized backscattered radiation was detected at $355 \mathrm{~nm}$ during EARLI09 (at $532 \mathrm{~nm}$ since the end of 2011).

CAML (Cloud and Aerosol Micro Lidar, ID: is01) of the Joint Research Centre (JRC), Ispra, Italy, is a commercial 
Table 2. Overview of measurement channels of EARLINET systems participating in the intercomparison campaigns; lidar IDs are as in Table 1. Numbers indicate detection wavelengths; $\mathrm{t}$ - total signal, $\mathrm{c}$ - cross-polarized signal, $\mathrm{p}$ - parallel-polarized signal, RR - rotational Raman signal, RY - HSRL Rayleigh signal, far - far-range receiver, near - near-range receiver, low - low-range receiver, pol - receiver for polarization measurements, $\mathrm{a}$ - analog detection, $\mathrm{p}$ - photon-counting detection, $\mathrm{a}+\mathrm{p}-\mathrm{combined}$ acquisition channels (Licel).

\begin{tabular}{|c|c|c|c|c|c|c|c|c|c|c|c|c|c|c|}
\hline Lidar & Rec. & $355 \mathrm{t}$ & $355 \mathrm{c}$ & $355 p$ & 355RR & 387 & 407 & $532 \mathrm{t}$ & $532 \mathrm{c}$ & $532 p$ & 532RY & 532RR & 607 & 1064 \\
\hline \multirow[t]{4}{*}{ hh01 } & far & $\mathrm{p}$ & & & $2 p$ & $\mathrm{p}$ & $\mathrm{p}$ & $\mathrm{p}$ & & & & $2 p$ & & $\mathrm{a}$ \\
\hline & near & $\mathrm{p}$ & & & $2 p$ & $\mathrm{p}$ & $\mathrm{p}$ & $\mathrm{p}$ & & & & $2 \mathrm{p}$ & & a \\
\hline & low & $\mathrm{p}$ & & & $2 p$ & & & $\mathrm{p}$ & & & & $2 p$ & & \\
\hline & pol & & & & & & & & $\mathrm{p}$ & $\mathrm{p}$ & & & & \\
\hline $\mathrm{ms} 01$ & & $\mathrm{a}$ & & & & $a+p$ & & & a & $\mathrm{a}$ & & & $a+p$ & a \\
\hline mu01 & & $(a+p)^{a}$ & $(a+p)^{a}$ & $(a+p)^{a}$ & & $(a+p)^{a}$ & & & & & & & & \\
\hline po01 & & $a+p$ & & & & $a+p$ & & & $a+p$ & $a+p$ & & & $a+p$ & $\mathrm{a}$ \\
\hline $\operatorname{mi01}$ & & $\mathrm{a}$ & & & & $\mathrm{p}$ & & $\mathrm{a}$ & & $\mathrm{a}$ & & & $\mathrm{p}$ & $\mathrm{a}$ \\
\hline le01 & & $\mathrm{p}$ & & & & $\mathrm{p}$ & $\mathrm{p}$ & $\mathrm{p}$ & $\mathrm{p}$ & & & $2 p$ & $\mathrm{p}$ & $\mathrm{p}$ \\
\hline le02 & & $\mathrm{p}$ & $\mathrm{p}$ & & & $\mathrm{p}$ & & $\mathrm{a}, \mathrm{p}$ & & & & & $\mathrm{p}$ & $\mathrm{p}$ \\
\hline is 01 & & & & & & & & $\mathrm{p}$ & & & & & & \\
\hline bu01 & & $a+p$ & & & & $a+p$ & $\mathrm{p}$ & & $a+p$ & $a+p$ & & & $a+p$ & a \\
\hline gp01 & & $\mathrm{a}$ & & & & & & $\mathrm{a}$ & & & $\mathrm{a}$ & & & a \\
\hline \multirow[t]{3}{*}{$\mathrm{ca} 01$} & far & $a+p$ & & & & $a+p$ & $\mathrm{p}$ & $a+p$ & & & & & $a+p$ & a \\
\hline & near & $a+p$ & & & & $a+p$ & $\mathrm{p}$ & $a+p$ & & & & & $a+p$ & a \\
\hline & pol & & & & & & & & $a+p$ & $a+p$ & & & & \\
\hline gr01 & & $a+p$ & & & & $\mathrm{p}$ & $\mathrm{p}$ & & $a+p$ & $a+p$ & & & $\mathrm{p}$ & $\mathrm{a}$ \\
\hline ev01 & & $\mathrm{p}$ & & & & $\mathrm{p}$ & & $\mathrm{p}$ & $\mathrm{p}$ & & & & $\mathrm{p}$ & $\mathrm{p}$ \\
\hline $\mathrm{ma01}$ & & $\mathrm{a}$ & & & & $a+p$ & & $\mathrm{a}$ & & & & & $a+p$ & a \\
\hline $\mathrm{ba02}$ & & $a+p$ & & & & $a+p$ & $a+p$ & $a+p$ & & & & & $a+p$ & a \\
\hline an01 & & $a+p$ & & & & $a+p$ & & & $a+p$ & $a+p$ & & & $a+p$ & a \\
\hline sf01 & & & & & & & & $\mathrm{p}^{\mathrm{b}}$ & & & & & & \\
\hline sf02 & & & & & & & & a & & & & & & a \\
\hline $\mathrm{la} 01$ & & $\mathrm{p}^{\mathrm{c}}$ & & & & $\mathrm{p}^{\mathrm{c}}$ & $\mathrm{p}^{\mathrm{c}}$ & & & & & & & \\
\hline na01 & & $\mathrm{a}, \mathrm{p}$ & & & & $\mathrm{p}, \mathrm{p}$ & $\mathrm{p}$ & & $a, p$ & $\mathrm{a}, \mathrm{p}$ & & & $\mathrm{p}$ & \\
\hline $\mathrm{lc} 01$ & & $a+p$ & $a+p$ & & & $a+p$ & $\mathrm{p}$ & $a+p$ & & & & & $a+p$ & $\mathrm{a}$ \\
\hline
\end{tabular}

a alternative configurations; see text for details

b $\mathrm{CuBr}$ laser, emission wavelength at $510 \mathrm{~nm}$

c XeF excimer laser, emission wavelength at $351 \mathrm{~nm}$, Raman-shifted wavelengths at 382 and $403 \mathrm{~nm}$

micropulse lidar supplied by Cimel Electronique. The automatic stand-alone system uses an $8 \mu \mathrm{J}, 4.7 \mathrm{kHz} \mathrm{Nd}$ :YAG laser and a $200 \mathrm{~mm}$ telescope, and it measures $532 \mathrm{~nm}$ elasticbackscatter light with a photon-counting APD (Barnaba et al., 2010).

RALI (Raman Aerosol Lidar, ID: bu01) of the National Institute of Research and Development of Optoelectronics, INOE 2000, Bucharest, Romania, is a commercial $3+2$ Raman lidar from Raymetrics (LR331-D400), including polarization discrimination at $532 \mathrm{~nm}$ and a water-vapor detection channel at $407 \mathrm{~nm}$. It applies a $330 \mathrm{~mJ}$ laser (Big Sky, CFR400-10) and a $400 \mathrm{~mm}$ Cassegrain telescope. The detection channels are based on Licel/Hamamatsu PMTs for the UV and visible channels and on a Licel/EG\&G APD at $1064 \mathrm{~nm}$ (Nemuc et al., 2013; Belegante et al., 2014).

IMK-IFU (Institut für Meteorologie und KlimaforschungAtmosphärische Umweltforschung, Karlsruhe Institute of
Technology) participated in EARLI09 with a newly developed $532 \mathrm{~nm}$ High Spectral Resolution Lidar (HSRL, ID: gp01). The 3+1 lidar (elastic-backscatter signals at 355, $532,1064 \mathrm{~nm}$ and Rayleigh signal at $532 \mathrm{~nm}$ ) applies a $0.5 \mathrm{~J}$ Nd:YAG laser (Quanta Ray, LAB-150-30) and a $300 \mathrm{~mm}$ Cassegrain telescope. The Rayleigh signal in the second $532 \mathrm{~nm}$ channel is separated with an iodine filter. Analog signal detection with actively stabilized Hamamatsu 7400-03 PMTs and a pin photodiode at $1064 \mathrm{~nm}$ (both from Romanski Sensors) is utilized.

CAELI, the CESAR (Cabauw Experimental Site for Atmospheric Research) Water Vapor, Aerosol, and Cloud Lidar (ID: ca01), was developed by the National Institute for Public Health and the Environment (RIVM), Bilthoven, the Netherlands, and is now operated by the Royal Netherlands Meteorological Institute (KNMI), De Bilt, the Netherlands (Apituley et al., 2009). CAELI works with a 1.6 J Nd:YAG laser 
(Continuum, PowerLite Precision II 9030 SI) and has two $3+2$ setups with a water-vapor Raman channel, one coupled to a $150 \mathrm{~mm}$ Newton telescope for near-range measurements and one to a $570 \mathrm{~mm}$ Newton telescope for far-range observations. In addition, a $50 \mathrm{~mm}$ lens telescope is used to measure parallel- and cross-polarized $532 \mathrm{~nm}$ signals. Licel data acquisition technique with Hamamatsu PMTs for the UV and visible wavelength range and EG\&G APDs for $1064 \mathrm{~nm}$ is applied in all channels.

\subsection{SPALI10 - Spanish Lidar Intercomparison 2010}

The second dedicated intercomparison campaign brought together the EARLINET systems of the Iberian peninsula from the stations in Évora, Barcelona, Madrid, and Granada. Comparisons were made against the reference system MUSA from CNR-IMAA in Potenza (ID: po01), which was successfully tested in EARLI09 before. The campaign called SPALI10 took place at the Centro de Investigaciones Energéticas, Medioambientales y Tecnológicas (CIEMAT), Department of Environment, Atmospheric Pollution Division, in Madrid, Spain, between 18 October and 5 November 2010. The campaign strategy followed the rules established in EARLI09. The first week of the campaign was used for instrument setup and tests of the automated preprocessing of data (see Sect. 3). During the following 2 weeks, measurement sessions were regularly scheduled during day and night. All in all, 29 sessions of $1-3 \mathrm{~h}$ duration were performed. Radiosondes were launched systematically during the whole field campaign for each measurement session.

All systems of the SPALI10 campaign are multiwavelength Raman lidars (see Tables 1 and 2). The Granada group operates a Raymetrics LR331-D400 system (ID: gr01) with specification as described for the Bucharest system above (Guerrero-Rascado et al., 2008, 2009). PAOLI (Portable Aerosol and Cloud Lidar, ID: ev01) from Évora is a $3+2$ system of Polly ${ }^{X T}$ type (Althausen et al., 2009) with a $450 \mathrm{~mJ}$ $\mathrm{Nd}$ :YAG laser (Continuum, Inlite III) and a $300 \mathrm{~mm}$ Newton telescope. Hamamatsu photon-counting-only PMTs are applied in all channels. Cross-polarized backscattered radiation, together with a total signal, is detected at $532 \mathrm{~nm}$. The LIDAR-CIEMAT system (ID: ma01) from Madrid and the UPC MRL (Universitat Politècnica de Catalunya Multispectral elastic-Raman Lidar, ID: ba02) from Barcelona are both $3+2$ systems without polarization discrimination, but with a water-vapor channel in the case of UPC MRL. LIDARCIEMAT makes use of a $1 \mathrm{~J}$ Spectra Physics laser (LAB-17030) and a $300 \mathrm{~mm}$ Newtonian telescope. UPC MRL applies a $365 \mathrm{~mJ}$ laser (Quantel, Brilliant) and a $355 \mathrm{~mm}$ SchmidtCassegrain telescope (Kumar et al., 2011). The detection channels of both systems are based on the Licel/Hamamatsu PMT and Licel/EG\&G APD acquisition systems.

\subsection{Single-site intercomparison campaigns}

Further intercomparisons were performed by moving one of the reference systems to specific EARLINET sites. Actually, this is the basic strategy applied for EARLINET intercomparisons at instrument level. It is planned to continue these kinds of intercomparisons over the years in order to validate each EARLINET system with a reference system from time to time. Nevertheless, respective efforts are large and require appropriate funding. Five activities were carried out between 2009 and 2013.

From 22 October to 5 November 2009 the reference system ARL2-mobile of MPI Hamburg (ID: hh01) was stationed at Andøya, Norway, in order to compare the Alomar Tropospheric Lidar (ID: al01). During ALI09 (Alomar Lidar Intercomparison 2009) simultaneous measurements were performed on nine days. On two days (4 and 5 November) radiosondes were launched to support the signal calibration. The Alomar Tropospheric Lidar is a $3+2$ multiwavelength Raman lidar with a $1 \mathrm{~J}$ laser (Spectra Physics, GCR-6-30) and a $175 \mathrm{~mm}$ Newtonian telescope. The data acquisition is based on the Licel/Hamamatsu PMT and Licel/EG\&G APD concepts. The optical receiver of the Alomar Tropospheric Lidar had been changed considerably in the time before the intercomparison, and the campaign was also used to fix remaining technical issues.

The lidar intercomparison SOLI10 (Sofia Lidar Intercomparison 2010) took place at the Institute of Electronics, Bulgarian Academy of Sciences (IE-BAS), in Sofia, Bulgaria, between 9 and 14 October 2010. POLIS from LMU Munich (ID: mu01) served as the reference system. POLIS had been upgraded to three channels in summer 2010, including $355 \mathrm{~nm}$ with polarization discrimination and either $532 \mathrm{~nm}$ total or $387 \mathrm{~nm}$, and had been intercompared with the reference lidar system MULIS (ID: ms01) in Maisach again. POLIS was transported to Sofia to intercompare both lidar systems of IE-BAS, one working with a $0.1 \mathrm{~mJ} \mathrm{CuBr}$ vapor laser at $510 \mathrm{~nm}$, and the other with a $1 \mathrm{~J} \mathrm{Nd}$ :YAG laser (EKSMA) at 532 and $1064 \mathrm{~nm}$ (Stoyanov et al., 2011). Both systems are elastic-backscatter lidars. The $\mathrm{CuBr}$ system (ID: sf01) uses a $150 \mathrm{~mm}$ Cassegrain telescope and a photon-counting PMT as the detector. The Nd:YAG system (ID: sf02) applies a $350 \mathrm{~mm}$ Cassegrain telescope and analog detection. The latter system points out of a lab window under $58^{\circ}$ zenith angle. Thus, the intercomparisons were made separately for the two systems, using the respective scan angle for the POLIS measurements.

The L'Aquila Lidar Intercomparison 2012, LALI12, was performed at the EARLINET site of the Dipartimento di Fisica, Università degli Studi dell'Aquila, in L'Aquila, Italy, between 10 and 15 September 2012. One daytime and three nighttime sessions covering one $60 \mathrm{~min}$ and six $30 \mathrm{~min}$ intercomparison periods were carried out. Also here, POLIS (ID: mu01) served as the reference system. The lidar at L'Aquila (ID: la01) is a UV aerosol and water-vapor lidar, which ap- 
plies a XeF excimer laser (Lambda Physik, EMG 150 MSC), a $200 \mathrm{~mm}$ telescope, and PMTs in photon-counting mode (Rizi et al., 2004). The emission wavelength is only slightly different from the third harmonic of a Nd:YAG laser, and thus the wavelength shift of the received elastic-backscatter $(351 \mathrm{~nm})$ and nitrogen Raman signals $(382 \mathrm{~nm})$ is neglected in the comparisons.

The lidar system MALIA (Multiwavelength Aerosol Lidar Apparatus, ID: na01) of the Consorzio Nazionale Interuniversitario per la Scienze Fisiche della Materia (CNISM) in Naples, Italy, was intercompared with the Potenza reference lidar MUSA (ID: po01) during the Naples Lidar Intercomparison 2013, NALI13, from 14 to 18 October 2013. Two daytime and three nighttime measurement periods of $30 \mathrm{~min}$ to $4 \mathrm{~h}$ were covered. MALIA is a 10 -channel system based on a $0.5 \mathrm{~J}$ Nd:YAG laser (Quantel, Brilliant-B) and a $0.3 \mathrm{~m}$ Newtonian telescope. Signals at $355 \mathrm{~nm}$ (total) and $532 \mathrm{~nm}$ (cross- and parallel-polarized) are detected with both photoncounting and analog channels. The Raman return at $387 \mathrm{~nm}$ is split to enter a high-signal and a low-signal photon-counting channel. Further photon-counting channels detect the Raman signals at 407 and $607 \mathrm{~nm}$. Data acquisition is based on $150 \mathrm{MHz}$ photon counters and 12 bit analog-digital converters.

From 21 to 25 October 2013, the Lecce Lidar Intercomparison LELI13 took place at the Università del Salento in Lecce, Italy. Again, the MUSA lidar (ID: po01) served as the reference system. Four daytime and five nighttime sessions were performed. The EARLINET station of Lecce operates a multiwavelength Raman lidar (UNILE lidar, ID: lc01) with a 1.4 J Nd:YAG laser (Quantel, YG981E) and a $0.3 \mathrm{~m}$ Newtonian telescope (Perrone et al., 2014). The $3+2$ system has polarization discrimination at $355 \mathrm{~nm}$ and a water-vapor Raman channel at $407 \mathrm{~nm}$. Licel data acquisition technique with Hamamatsu PMTs for the UV and visible wavelength range and an EG\&G APD for $1064 \mathrm{~nm}$ is applied in all channels.

\section{Measurement and data-processing strategies}

The participation of a relatively large number of lidar systems in an intercomparison campaign, like EARLI09 and SPALI10, requires the development and application of coordinated observation and data-evaluation strategies. For instance, it is necessary to have preliminary comparison results at hand as soon as possible after each measurement session in order to detect and remove system faults immediately. Particular attention must be paid in the beginning of a campaign when systems had been moved before. Specific care is also necessary when systems are brand new, as was the case in EARLI09 for the new reference systems. In addition, introducing differences in the comparisons by using different analysis software should be avoided. These considerations led to the development of a special version of the Single Calculus Chain (SCC, D’Amico et al., 2015, 2016) before
EARLI09 in order to preprocess the raw lidar data in a common way instantaneously. An additional piece of software, developed at LMU Munich, served for the direct comparison at signal level, i.e., necessary interpolation, smoothing, and weighting as well as visualization of signals and determination of signal deviations. Finally, a modified version of the SCC optical products module (Mattis et al., 2016) was used to calculate particle extinction and backscatter coefficients from the processed signals in order to perform comparisons at product level. The respective concepts are outlined in the following.

In all intercomparison campaigns the lidar systems were collocated on a flat terrain within about $100 \mathrm{~m}$ distance. The laser beams pointed close to the zenith (except sf02; see above), which made it very likely that all instruments measured the same atmospheric volume within the averaging time. Several sessions were scheduled for every day of the campaigns (weather permitting), one at daytime and one at night if possible. Each session lasted several hours with the goal to find at least a $30 \mathrm{~min}$ period in each session with stable atmospheric conditions and with all lidar systems up and running. In order to be as flexible as possible in the selection of final comparison periods, the raw signals were stored with 1 min resolution. The complete data sets of these raw signals from all systems had to be delivered without any preprocessing to a common database server shortly after each session.

The raw-signal formats had been predefined, following standards set for the EARLINET SCC. Each data set includes a header with all information necessary for further processing of the signals. Some basic, fixed parameters of each system had been collected in a system database. Using the header and database information, all signals were then preprocessed by the modified version of the SCC. The preprocessor performs trigger-delay shift, dead-time correction, background subtraction, and range correction. If requested, the preprocessor also combines near-range and far-range signals, photoncounting and analog signals (gluing), and parallel- and crosspolarized signals into a total profile using given calibration ranges or values. After this individual signal preprocessing and after selection of an appropriate comparison period, the signals were averaged, typically over 30 to $120 \mathrm{~min}$, in order to improve the signal-to-noise ratio.

Figure 2 illustrates the processing steps at signal level for the example of $387 \mathrm{~nm}$ signals measured with nine systems in eleven channels during EARLI09 on 25 May 2009, 21:00 23:00 UTC. The channels are distinguished by color, and the legend provides the system ID (see Table 1) as well as a three-digit channel ID with the following meaning: 
f__ _ signal from far-range telescope

$\mathrm{n} \_$_ $\quad$ signal from near-range telescope

1_ _ _ signal from low-range telescope

$\mathrm{x}$ _ _ _ signal from a system with one telescope

_t_ _ total signal

_p_ _ parallel-polarized signal

_c_ _ cross-polarized signal

_s_ _ _ sum of parallel- and cross-polarized signals

_a - analog signal

_ $\mathrm{p}$ - photon-counting signal

_ $\mathrm{g}$ - $\quad$ analog and photon-counting glued signal (Licel).

In Fig. 2a, the individual signals are shown after preprocessing with the SCC. Here, the averaged output signals provided by the SCC preprocessor still have the original range resolutions from 3.75 to $60 \mathrm{~m}$. In addition, a range offset may occur because of different lidar location altitudes above ground (e.g., when a lidar is operated in a building or on top of a building and compared against a reference system in a van or container at ground level). Furthermore, pointing angles of the systems are typically between 0 and $5^{\circ}$ and require further altitude corrections. In order to allow for a point-bypoint comparison, the signals were re-binned to a common height resolution of $60 \mathrm{~m}$ and to common height levels considering the individual system altitudes and the lidar zenith angles. The signal noise at higher altitudes was reduced by further stepwise progressive smoothing with up to $960 \mathrm{~m}$ resolution. The result is presented in Fig. 2b. In order to compare the signals quantitatively, they were normalized in the height range between 3.5 and $6.5 \mathrm{~km}$, where the deviations are small and the signal-to-noise ratios are high.

Usually, comparisons should be made against a reference system for all individual wavelengths and polarization states. However, in EARLI09, none of the reference systems were considered to be proven already. Therefore, the chosen strategy was to construct a mean signal, or common reference, from the best parts of all available signals. Ideally, this common reference should be close to the unknown true signal. For this purpose, range-dependent weights are assigned to the individual signals by an expert's guess reflecting an assumed accuracy; see Fig. 2c. A weight of zero means that the respective part of the signal, e.g., the range of incomplete overlap, is omitted. A weight of 1 is assigned to ranges that appear trustworthy. Then, a weighted mean signal is calculated as a first guess of the common reference. Afterwards, the expert's weights are successively decreased by a factor commensurate with the range-dependent signal deviation from the first-guess mean signal; see Fig. 2d. In this way, highest weights are assigned to the best signal parts, and the final common reference is calculated. In the stratosphere, where an aerosol-free range can be assumed, the mean signal is replaced by a calculated signal from actual radiosonde data (pure molecular Rayleigh or Raman signal), fitted to the common reference at an appropriate height (usually at about $15 \mathrm{~km}$ ). The radiosonde data were taken from local radiosonde ascents during the experiment.

The approach of a common reference was applied in EARLI09 only. In all other campaigns, the reference system was considered as the standard to which the other systems were compared. Point-by-point deviations as well as mean deviations in certain height ranges are used to assess the quality of the signals.

If $P_{\text {ref }}\left(z_{i}, \lambda\right)$ is the reference signal at wavelength $\lambda$ (either the common reference or the signal from the reference system), the relative deviation of an individual signal $P\left(z_{i}, \lambda\right)$ from this reference signal is calculated for each individual height $z_{i}$ (to which the signals were commonly binned) as

$\Delta P\left(z_{i}, \lambda\right)=\frac{P\left(z_{i}, \lambda\right)-P_{\mathrm{ref}}\left(z_{i}, \lambda\right)}{P_{\mathrm{ref}}\left(z_{i}, \lambda\right)}$.

The relative deviations are shown in Fig. 2e for the example case of 25 May 2009.

The mean relative systematic deviation (relative bias) of an individual signal from the reference signal over a height range $\Delta z=z_{L}-z_{K}$, i.e., $L-K+1$ height bins, is defined as

$\overline{\Delta P}(\Delta z, \lambda)=\frac{\sum_{i=K}^{L} \Delta P\left(z_{i}, \lambda\right)}{L-K+1}$.

The mean relative systematic deviation is used to assess the quality of signals in certain atmospheric height ranges (e.g., boundary layer, free troposphere, stratosphere).

For the comparison at product level, aerosol optical parameters were computed using a special version of the SCC optical products module (Mattis et al., 2016). This version is able to treat the preprocessed, re-binned, and normalized signals, and also the common reference, on the common height grid (with $60 \mathrm{~m}$ vertical resolution in EARLI09). Thus, point-bypoint comparisons and the calculation of mean deviations are possible for the products in the same way as for the signals. We use the absolute deviation,

$\Delta c\left(z_{i}, \lambda\right)=c\left(z_{i}, \lambda\right)-c_{\mathrm{ref}}\left(z_{i}, \lambda\right)$

of a coefficient $c$ (either extinction or backscatter coefficient) from the reference coefficient $c_{\text {ref }}$ at individual heights and the mean absolute systematic deviation (absolute bias) in certain height ranges,

$\overline{\Delta c}(\Delta z, \lambda)=\frac{\sum_{i=K}^{L} \Delta c\left(z_{i}, \lambda\right)}{L-K+1}$,

to investigate the quality of optical products. 
(a)

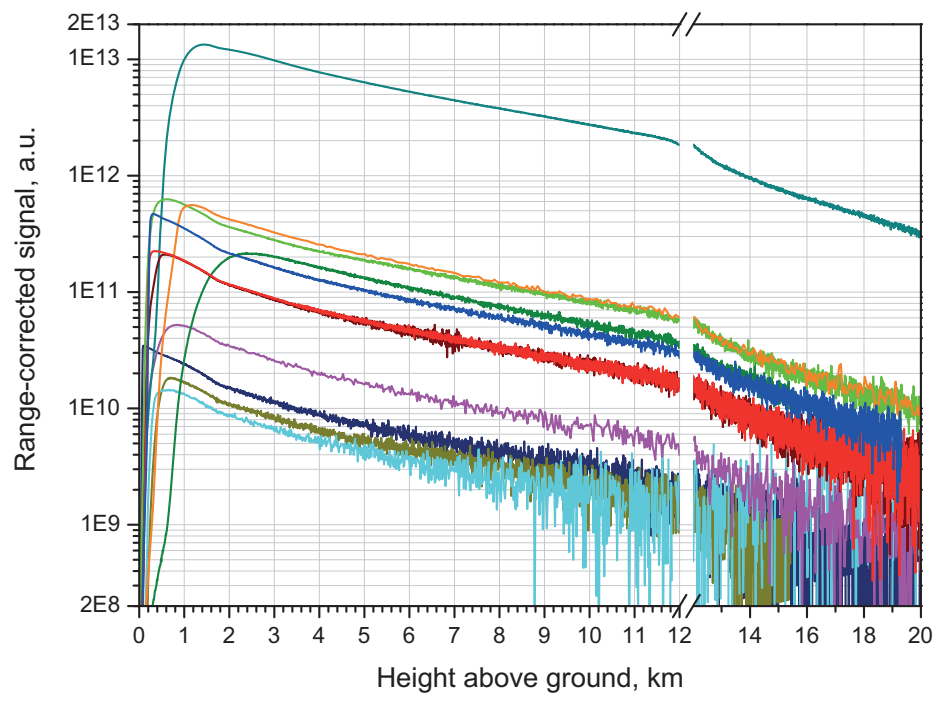

(b)

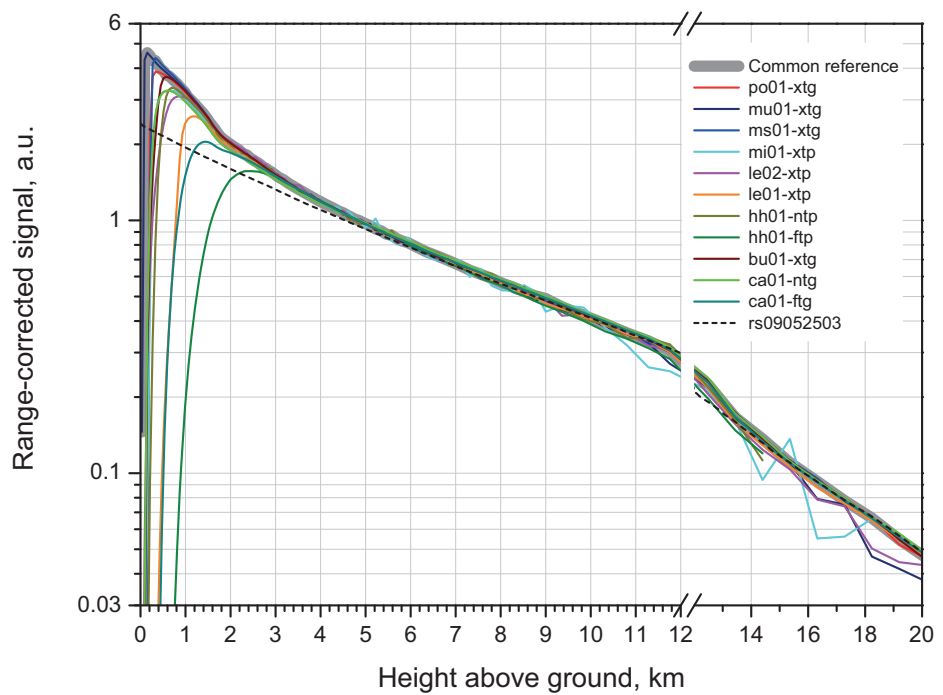

(c)

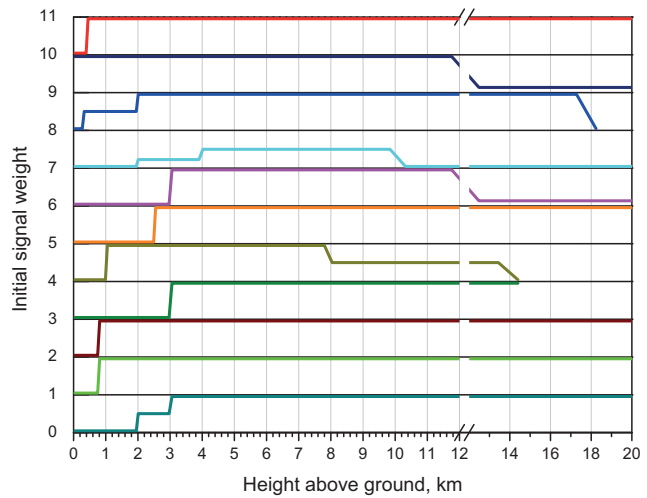

(d)

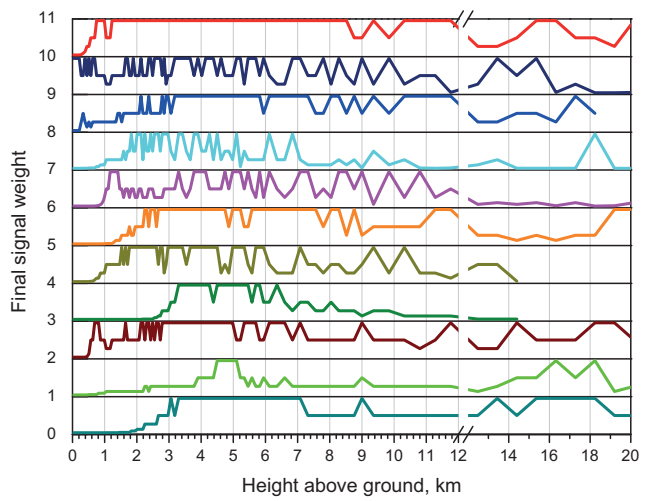

(e)

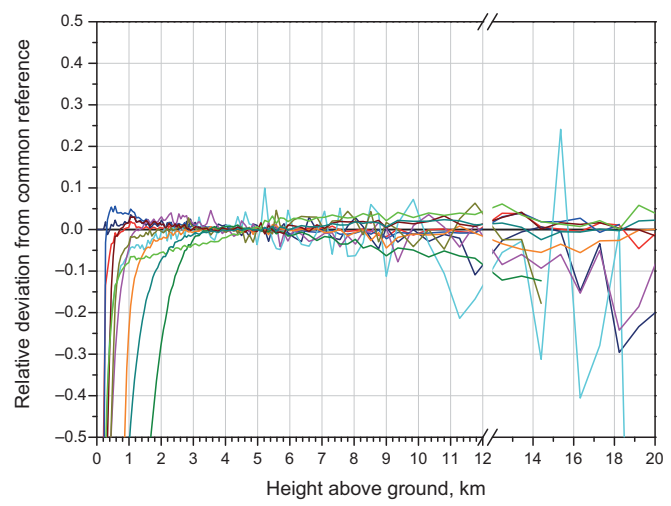

Figure 2. Illustration of signal processing for comparison purposes. The measurement was taken during EARLI09 on 25 May 2009, 21:0023:00 UTC. (a) Range-corrected signals at $387 \mathrm{~nm}$ with individual range resolutions (3.75 to $60 \mathrm{~m}$ ). (b) Range-corrected lidar signals at $387 \mathrm{~nm}$ binned to common height resolution $(60 \mathrm{~m})$ and to common height levels, progressively smoothed $(60 \mathrm{~m}$ up to $3 \mathrm{~km}$, $120 \mathrm{~m}$ from 3-6 km, $240 \mathrm{~m}$ from $6-9 \mathrm{~km}, 480 \mathrm{~m}$ from $9-12 \mathrm{~km}, 960 \mathrm{~m}$ above), and normalized between 3.5 and $6.5 \mathrm{~km}$. The thick gray line represents the common reference. A pure molecular signal at $387 \mathrm{~nm}$ calculated from radiosonde data (rs09052503) is fitted to the common reference at $10.3 \mathrm{~km}$ (shown below $12 \mathrm{~km}$ ) and, additionally, at $15.3 \mathrm{~km}$ (shown above $12 \mathrm{~km}$ ). (c) Initial weights assigned to the signals for calculation of a weighted mean signal. (d) Final weights assigned to the signals for calculation of the common reference. (e) Relative deviations of individual signals from the common reference. For the sake of conspicuity the weights in panels (c) and (d) are successively shifted by a value of 1 along the $y$ axis.

\section{Results}

In the following, we present comparison results at signal and product level. We focus on signals at the wavelengths of 355 (total), 387, 532 (total, parallel-, and cross-polarized), and $607 \mathrm{~nm}$ and respective aerosol products, i.e., particle extinction and backscatter coefficients at 355 and $532 \mathrm{~nm}$. We do not discuss observations at $1064 \mathrm{~nm}$, since there is a separate paper on technical solutions, calibration issues, and intercomparison results for the infrared wavelength in this special issue by Engelmann et al. (2016). Furthermore, we do not show results at product level for the particle depolarization ratio. Depolarization ratio measurements require specific calibration procedures, which are discussed in de- 
tail in this special issue by Bravo-Aranda et al. (2016) and Freudenthaler (2016). Rotational Raman lidar signals at 355 and $532 \mathrm{~nm}$ and the $532 \mathrm{~nm}$ HSRL Rayleigh signal are shown in conjunction with the respective vibration-rotation Raman signals at 387 and $607 \mathrm{~nm}$, respectively, if available. We do not compare signals at $407 \mathrm{~nm}$ (water-vapor Raman signals), neither do we show water-vapor and temperature retrievals, since these observations are currently not within the scope of EARLINET.

Quantitative comparisons are presented for selected measurement periods from each campaign. The periods were chosen such that the instruments showed a satisfactory performance; i.e., teething troubles as typical in the beginning of a campaign had already been solved. Mainly nighttime cases were considered, so that a complete evaluation of all measurement channels and all delivered products was possible. Note that the focus of EARLINET is on the provision of aerosol extinction and backscatter profiles independently derived with high accuracy from Raman lidar measurements during nighttime, since most of the Raman channels in the network cannot be operated in the presence of strong daylight. It was ensured that the atmospheric conditions had been stable over the measurement period, which is most likely the case during nighttime, and allow for unambiguous comparisons. Therefore, the profiles were also checked for the presence of a considerable amount of particles over a large height range as well as clear-air signatures in the far range representing Rayleigh conditions. Generally, cases with optically thick clouds were excluded. Figures illustrating point-by-point comparisons are presented for EARLI09 only, whereas tables provide results of mean systematic deviations in selected height ranges for all intercomparison campaigns. Interested readers may find additional information on different intercomparison campaigns in the ACTRIS QA reports; see, e.g., Deliverables D2.5 and D2.11 of the ACTRIS FP7 project provided at http://fp7.actris.eu/language/en-GB/ Members/Deliverables.aspx.

\subsection{Comparisons at signal level}

Figures 3 and 4 show comparison results for the EARLI09 session of 25 May 2009, 21:00-23:00 UTC. On that day, Saharan dust layers were present up to about $6.5 \mathrm{~km}$ height and provided a good opportunity for detailed comparisons of aerosol products over a large height range. A cirrus cloud layer occurred between 11 and $13.5 \mathrm{~km}$ height. The left panels of Figs. 3 and 4 show the signals at 355, 387, and $607 \mathrm{~nm}$ and the total, cross-polarized, and parallel-polarized $532 \mathrm{~nm}$ signals, respectively. The right panels of both figures present the relative signal deviations from the common reference. The applied methodology follows the explanations in Sect. 3 exactly (see Fig. 2).

The different geometrical overlap functions of the various systems and channels are clearly visible. Whereas nearrange channels based on a small telescope and a wide field of view reach a complete overlap at a few hundred meters above ground, channels based on a large-sized telescope and a small field of view obtain full geometrical overlap between 1 and $3.5 \mathrm{~km}$. The latter channels are usually well suited for observations in the lower stratosphere up to $20-30 \mathrm{~km}$ height, whereas the near-range channels are typically limited to measurements in the troposphere, as can be seen in the figures from the large fluctuations due to low signal-to-noise ratios above the cirrus layer. In order to account for the different observation ranges, for each channel a valid range is defined within which the mean deviations from the reference are calculated. The minimum valid range is the height below which the signal has a systematic relative deviation of $>0.1$ from the reference profile, usually due to incomplete overlap. The maximum valid range is the height above which the mean relative deviation from the reference profile is $>0.1$ over a height interval of $2 \mathrm{~km}$, usually when the detection limit is reached. This upper boundary is determined by the instrument parameters as well as by the actual atmospheric conditions, in particular the optical depth. In the present case, the attenuation of the signals by the cirrus cloud deck leads to generally lower maximum valid ranges compared to observations under clear conditions.

Tables 3 and 4 show the valid range and the mean relative signal deviation for different height ranges for the EARLI09 case of 25 May 2009 as well as for all other comparison campaigns. The height ranges are defined from the lowest valid range to $2.5 \mathrm{~km}$ (R1, typically covering the planetary boundary layer), from 2.5 to $6 \mathrm{~km}$ (R2, representing the lower troposphere), from 6 to $12 \mathrm{~km}$ (R3, representing the upper troposphere), and from $12 \mathrm{~km}$ to the highest valid range (R4, indicating the system performance in the lower stratosphere). If the lower valid range is above $2.5 \mathrm{~km}$ and/or the upper valid range is below $12 \mathrm{~km}$, the averaging is applied accordingly to the respective valid ranges, and the excluded ranges (R1 ... R4) are indicated as not valid (n.v.). As mentioned above, the concept of a common reference was applied only in EARLI09. For all other campaigns the deviations are calculated with respect to the reference system or, for stratospheric heights and when the reference system was at the detection limit, with respect to the Rayleigh profile derived from radiosonde observations.

Regarding EARLI09 Figs. 3 and 4 and Tables 3 and 4 show a good agreement for almost all systems. Within the valid range the mean systematic signal deviations are, with few exceptions, well below $\pm 5 \%$ and typically in the range of $\pm 2 \%$. Best agreement is found in the lower troposphere (R2). In this range, the mean deviations are mostly below $1 \%$. Largest deviations are obtained in the lowest and highest ranges, close to the boundaries which define the valid range, and can thus be attributed to the effects of incomplete overlap or low signal-to-noise ratio. A clear bias due to obvious system misalignment was found for the CAML micropulse lidar from Ispra (is01, see Fig. 4 and Table 4). Since this commercial system is sealed, no technical corrections by the 
Table 3. Valid range and mean systematic deviation of signals at 355, 387, and $607 \mathrm{~nm}$ in four height ranges: R1 (lowest valid range- $2.5 \mathrm{~km}$ ), R2 (2.5-6 km), R3 (6-12 km), and R4 (12 km-highest valid range). n.v. denotes not valid. Rec. denotes receiver range.

\begin{tabular}{|c|c|c|c|c|c|c|c|c|c|c|c|c|c|c|c|c|}
\hline \multirow[t]{2}{*}{ Lidar } & \multirow[t]{2}{*}{ Rec. } & \multirow{2}{*}{$\begin{array}{l}\text { Valid } \\
\text { range, } \\
\mathrm{km}\end{array}$} & \multicolumn{4}{|c|}{$\begin{array}{c}\text { Mean systematic deviation, } \% \\
355 \mathrm{~nm} \text { (total) }\end{array}$} & \multirow{2}{*}{$\begin{array}{c}\text { Valid } \\
\text { range, } \\
\text { km }\end{array}$} & \multicolumn{4}{|c|}{$\begin{array}{l}\text { Mean systematic deviation, } \% \\
387 \mathrm{~nm}\end{array}$} & \multirow[t]{2}{*}{$\begin{array}{l}\text { Valid } \\
\text { range, }\end{array}$} & \multicolumn{4}{|c|}{$\begin{array}{c}\text { Mean systematic deviation, \% } \\
607 \mathrm{~nm}\end{array}$} \\
\hline & & & $\mathrm{R} 1$ & $\mathrm{R} 2$ & $\mathrm{R} 3$ & $\mathrm{R} 4$ & & R1 & $\mathrm{R} 2$ & R3 & $\mathrm{R} 4$ & & $\mathrm{R} 1$ & $\mathrm{R} 2$ & R3 & R4 \\
\hline \multirow[t]{3}{*}{ hh01 } & far & $2.8-14.4$ & n.v. & -1.2 & -1.7 & -8.5 & $2.5-14.4$ & n.v. & -0.5 & -3.8 & -12.0 & - & - & - & - & - \\
\hline & near & $0.7-14.4$ & -1.9 & +0.0 & -0.5 & +2.8 & $0.7-14.4$ & -1.7 & +0.1 & +1.3 & -7.5 & - & - & - & - & - \\
\hline & low & $1.0-14.4$ & +3.0 & +0.2 & +0.1 & +5.8 & - & - & - & - & - & - & - & - & - & - \\
\hline ms01 & & $0.3-12.5$ & -0.3 & -0.9 & +4.9 & n.v. & $0.3-18.0$ & +2.5 & +0.4 & -0.8 & +2.0 & $0.3-18.0$ & +0.7 & +0.2 & -0.5 & +1.1 \\
\hline mu01 & & $0.2-16.0$ & +2.3 & +0.4 & +3.4 & -0.6 & $0.2-16.0$ & +1.3 & +0.3 & -1.5 & -3.6 & - & - & - & - & - \\
\hline po01 & & $0.3-30.0$ & -1.7 & -0.0 & -0.2 & -0.4 & $0.3-30.0$ & -0.4 & +0.0 & -0.3 & -4.2 & $0.3-12.0$ & +4.4 & +0.5 & -1.5 & n.v. \\
\hline mi01 & & $0.4-20.0$ & +0.8 & +0.3 & +0.5 & +7.2 & $0.7-14.0$ & -3.5 & +0.2 & -3.5 & -4.2 & $0.5-15.0$ & -2.8 & -0.2 & -0.6 & +2.1 \\
\hline le01 & & $1.3-30.0$ & +0.3 & +0.4 & -1.1 & -0.1 & $1.3-30.0$ & -3.5 & -0.2 & -0.9 & -1.9 & $1.5-30.0$ & -4.9 & -0.6 & +0.3 & -1.6 \\
\hline le02 & & $0.8-15.0$ & +1.2 & +1.1 & +0.4 & +0.4 & $0.8-15.0$ & +1.8 & +0.8 & -1.2 & -7.4 & $0.8-15.0$ & +2.1 & +0.7 & -1.6 & -5.0 \\
\hline bu01 & & $0.5-25.0$ & -1.1 & -0.4 & +0.8 & -1.5 & $0.5-25.0$ & +0.0 & +0.2 & +1.4 & -0.4 & $0.4-15.0$ & +9.1 & +1.8 & -1.3 & -7.0 \\
\hline gp01 & & & -6.1 & -2.6 & & & - & - & - & - & - & - & - & - & - & - \\
\hline \multirow[t]{2}{*}{$\mathrm{ca} 01$} & far & $1.9-30.0$ & -5.7 & -0.7 & +2.1 & -1.9 & $1.9-30.0$ & -5.3 & -0.6 & -0.6 & -0.3 & $1.3-30.0$ & -3.5 & -0.2 & +1.2 & -1.5 \\
\hline & near & $0.6-28.0$ & -1.5 & -0.3 & +1.1 & -2.9 & $0.8-28.0$ & -6.4 & -1.4 & +3.2 & +1.6 & $0.3-12.0$ & -1.4 & -0.5 & +2.9 & n.v. \\
\hline gr01 & & -30.0 & & -0.2 & & & $3-30.0$ & +2.6 & -0.8 & +0.9 & +0.1 & $3-20.0$ & -7.3 & -2.2 & +0.3 & +1.6 \\
\hline ev01 & & $2.8-30.0$ & n.v. & +3.8 & +1.6 & -0.7 & $2.1-30.0$ & +7.8 & +3.5 & -0.1 & -1.2 & $1.0-30.0$ & -1.4 & -2.3 & +0.2 & -0.7 \\
\hline ma01 & & $0.7-12.0$ & +1.6 & +2.2 & -3.7 & n.v. & - & n.v. & n.v. & n.v. & n.v. & - & n.v. & n.v. & n.v. & n.v. \\
\hline ba02 & & $0.5-30.0$ & +7.0 & +3.0 & +0.5 & -0.3 & $0.9-30.0$ & -2.2 & -2.1 & -0.1 & -0.7 & $0.8-30.0$ & -3.7 & -3.4 & -0.3 & -1.9 \\
\hline an01 & & $0.3-8.0$ & -1.4 & -0.3 & -4.0 & II.v. & $0.5-7.0$ & -1.7 & -0.5 & +0.2 & n.v. & - & n.v. & n.v. & n.v. & n.v. \\
\hline la01* & & $0.3-13.0$ & +0.9 & +0.2 & -1.1 & +2.7 & $0.3-13.0$ & +2.0 & +0.0 & -0.2 & +2.0 & - & - & 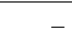 & 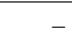 & - \\
\hline na01 & & $0.7-18.0$ & -0.4 & -0.8 & -1.0 & -1.4 & $0.7-18.0$ & -1.7 & -0.1 & -1.6 & -8.1 & $0.7-12.0$ & -3.0 & -1.5 & +8.6 & n.v. \\
\hline $\mathrm{lc} 01$ & & $0.9-13.0$ & +0.2 & +0.3 & +0.7 & -3.6 & $0.3-15.0$ & -1.4 & -0.4 & +0.6 & -2.0 & $0.3-12.0$ & -3.4 & -0.7 & +5.2 & n.v. \\
\hline
\end{tabular}

* XeF excimer laser; the wavelengths are $351 \mathrm{~nm}$ and $382 \mathrm{~nm}$.

Table 4. Valid range and mean systematic deviation of signals at $532 \mathrm{~nm}$ (total), $532 \mathrm{~nm}$ (cross-polarized), and $532 \mathrm{~nm}$ (parallel-polarized) in four height ranges: R1 (lowest valid range-2.5 km), R2 (2.5-6 km), R3 $(6-12 \mathrm{~km})$, and R4 (12 km-highest valid range). n.v. denotes not valid. NA denotes not available. Rec. denotes receiver range.

\begin{tabular}{|c|c|c|c|c|c|c|c|c|c|c|c|c|c|c|c|c|}
\hline \multirow[t]{2}{*}{ Lidar } & \multirow[t]{2}{*}{ Rec. } & \multirow{2}{*}{$\begin{array}{c}\text { Valid } \\
\text { range, } \\
\mathrm{km}\end{array}$} & \multicolumn{4}{|c|}{$\begin{array}{l}\text { Mean systematic deviation, \% } \\
532 \mathrm{~nm} \text { (total) }\end{array}$} & \multirow{2}{*}{$\begin{array}{c}\text { Valid } \\
\text { range, } \\
\mathrm{km}\end{array}$} & \multicolumn{4}{|c|}{$\begin{array}{l}\text { Mean systematic deviation, } \% \\
532 \mathrm{~nm} \text { (cross-polarized) }\end{array}$} & \multirow{2}{*}{$\begin{array}{l}\text { Valid } \\
\text { range, } \\
\mathrm{km}\end{array}$} & \multicolumn{4}{|c|}{$\begin{array}{l}\text { Mean systematic deviation, \% } \\
532 \mathrm{~nm} \text { (parallel-polarized) }\end{array}$} \\
\hline & & & $\mathrm{R} 1$ & $\mathrm{R} 2$ & $\mathrm{R} 3$ & $\mathrm{R} 4$ & & $\mathrm{R} 1$ & $\mathrm{R} 2$ & $\mathrm{R} 3$ & $\mathrm{R} 4$ & & $\mathrm{R} 1$ & $\mathrm{R} 2$ & $\mathrm{R} 3$ & $\mathrm{R} 4$ \\
\hline \multirow[t]{4}{*}{ hh01 } & far & $2.0-12.5$ & -0.6 & +2.6 & -8.5 & n.v. & - & - & - & - & - & - & - & - & - & - \\
\hline & near & $1.6-14.4$ & +4.7 & +0.7 & +0.3 & +1.1 & - & - & - & - & - & - & - & - & - & - \\
\hline & low & $2.0-14.4$ & +8.9 & +1.9 & -1.7 & +5.6 & - & - & - & - & - & - & - & - & - & - \\
\hline & pol & - & - & - & - & - & $0.5-14.4$ & +16.0 & +10.0 & -38.0 & -140.0 & $0.5-14.4$ & +10.0 & +1.7 & -6.2 & -40.0 \\
\hline $\mathrm{ms} 01$ & & $0.3-13.5$ & +1.5 & -0.0 & -0.1 & +2.6 & $0.3-18.0$ & +5.2 & +6.2 & -21.0 & -30.0 & $0.3-14.0$ & +1.1 & -0.7 & -0.3 & -3.5 \\
\hline po01 & & $0.3-20.0$ & -1.2 & -0.1 & -0.2 & +5.9 & $0.3-20.0$ & +3.8 & +2.7 & -4.3 & -10.0 & $0.3-20.0$ & -1.6 & -0.8 & +0.4 & +3.1 \\
\hline $\mathrm{mi01}$ & & $0.4-20.0$ & -2.0 & -0.8 & +0.4 & -1.2 & - & - & - & - & - & $0.4-20.0$ & +0.3 & +0.7 & -0.7 & +0.3 \\
\hline le01 & & $1.2-28.0$ & +2.0 & -0.3 & +2.6 & +5.4 & $1.3-30.0$ & -11.0 & -6.5 & +31.0 & +2.0 & - & - & - & - & - \\
\hline le02 & & $0.8-15.0$ & +0.5 & -0.2 & -0.6 & -7.3 & - & - & - & - & - & - & - & - & - & - \\
\hline is 01 & & $(1.5-12.0)$ & +5.1 & +3.6 & -15.0 & n.v. & - & - & - & - & - & - & - & - & - & - \\
\hline bu01 & & $0.4-25.0$ & +4.3 & -0.3 & +0.1 & -3.6 & $0.4-30.0$ & +9.3 & -6.1 & +34.0 & -1.9 & $0.4-20.0$ & +4.7 & +0.5 & -0.8 & -5.6 \\
\hline gp01 & & $2.5-12.0$ & n.v. & +2.6 & -0.1 & n.v. & - & - & - & - & - & - & - & - & - & - \\
\hline \multirow[t]{3}{*}{$\mathrm{ca} 01$} & far & $1.4-26.0$ & -3.9 & -0.3 & +0.4 & -5.2 & - & - & - & - & - & - & - & - & - & - \\
\hline & near & $0.2-25.0$ & -0.3 & -0.1 & +1.6 & +0.8 & - & - & - & - & - & - & - & - & - & - \\
\hline & pol & - & - & - & - & - & $0.5-25.0$ & +3.8 & -1.8 & +16.0 & -7.5 & $0.3-25.0$ & -5.8 & -1.4 & +1.7 & +1.2 \\
\hline gr01 & & $0.5-30.0$ & -4.3 & -1.7 & +1.0 & -0.4 & $1.0-30.0$ & -3.4 & +3.8 & +0.1 & -0.4 & $0.5-30.0$ & -2.6 & -0.7 & -0.2 & -0.3 \\
\hline ev01 & & $1.1-30.0$ & -1.2 & +1.1 & +1.5 & -1.9 & - & NA & NA & NA & NA & - & - & - & - & - \\
\hline ma01 & & $0.3-25.0$ & -3.3 & -0.3 & +0.3 & -2.9 & - & - & - & - & - & - & - & - & - & - \\
\hline ba02 & & $2.0-30.0$ & -8.3 & -3.3 & +1.6 & -0.6 & - & - & - & - & - & - & - & - & - & - \\
\hline an01 & & - & - & - & - & - & $0.5-7.0$ & +0.9 & -10.0 & +3.7 & n.v. & $1.0-12.0$ & -5.7 & -0.1 & -8.4 & n.v. \\
\hline sf01* & & $1.3-10.0$ & +0.4 & -5.0 & -7.7 & n.v. & - & - & - & - & - & - & - & - & - & - \\
\hline sf02 & & $0.2-12.0$ & +0.5 & +0.3 & +7.5 & n.v. & - & - & - & - & - & - & - & - & - & - \\
\hline na01 & & $1.0-15.0$ & -0.3 & -0.2 & -2.0 & -3.3 & $1.0-13.0$ & +2.6 & -2.2 & +0.9 & +9.1 & $1.0-15.0$ & -0.8 & -0.1 & -1.9 & +2.9 \\
\hline lc01 & & $1.2-15.0$ & +3.9 & +0.4 & +0.2 & +5.6 & - & - & - & - & - & - & - & - & - & - \\
\hline
\end{tabular}

* $\mathrm{CuBr}$ laser; the wavelength is $510 \mathrm{~nm}$. 
(a)

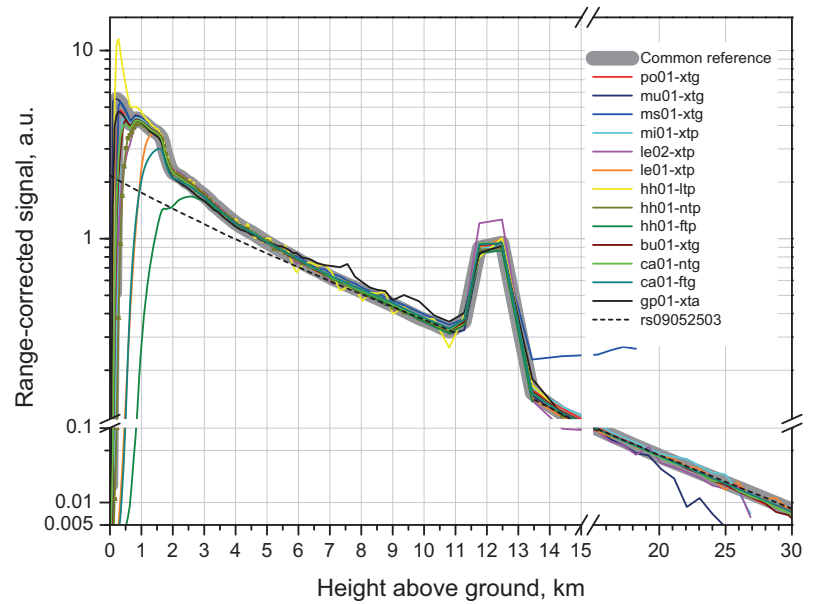

(c)

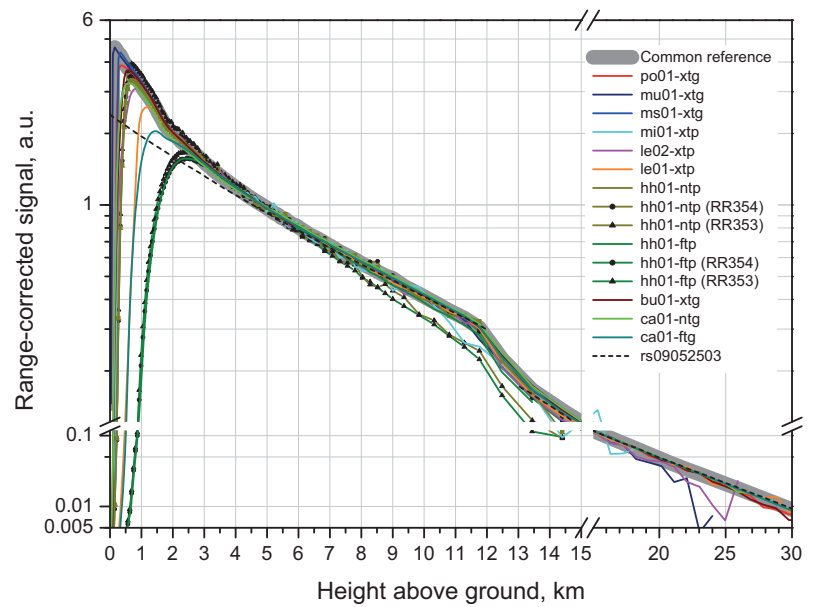

(e)

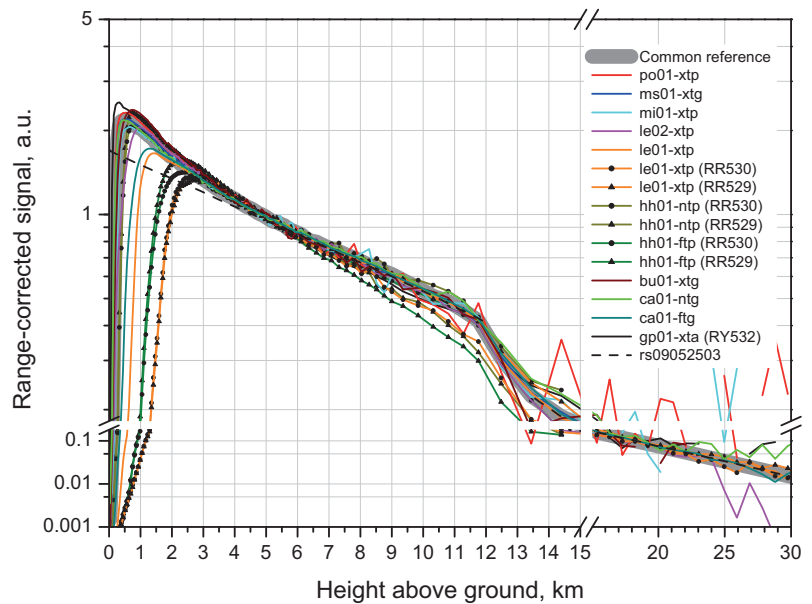

(b)

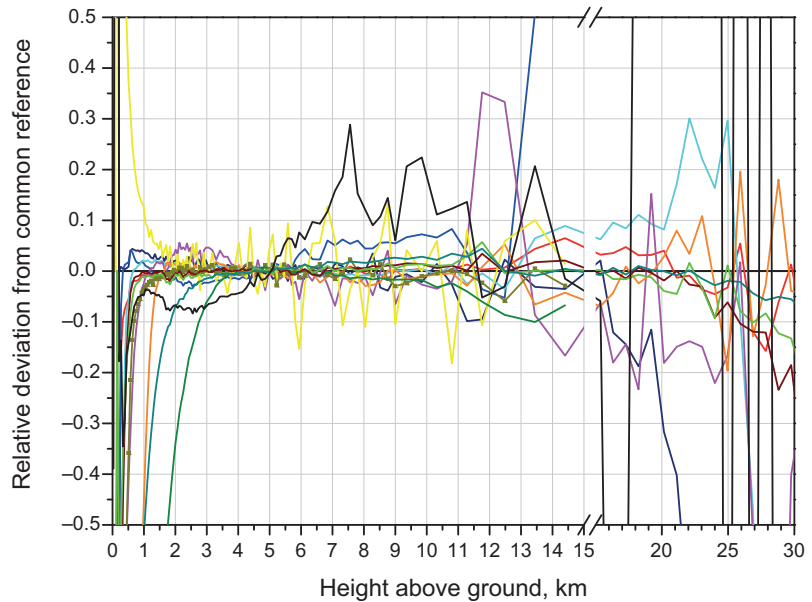

(d)

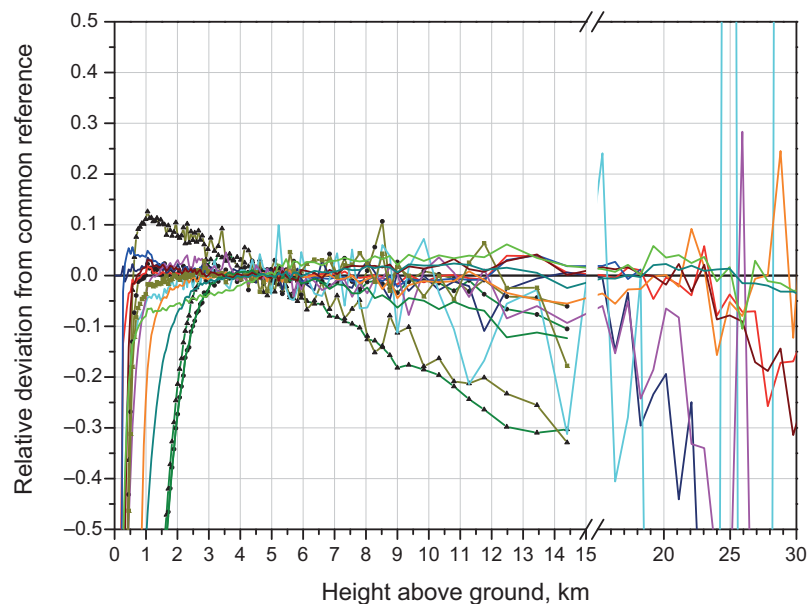

(f)

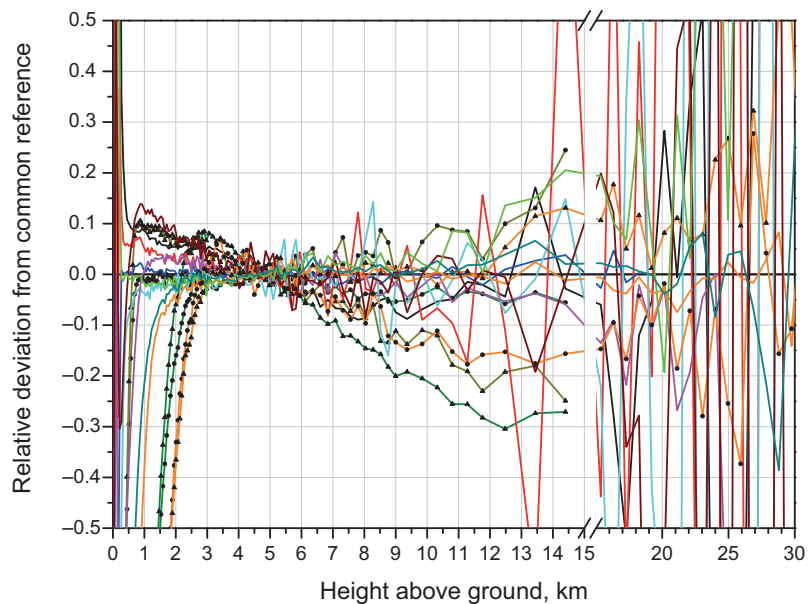

Figure 3. Comparison of range-corrected signals at (a) $355 \mathrm{~nm}$, (c) $387 \mathrm{~nm}$, and (e) $607 \mathrm{~nm}$ and their deviations from the common reference (b, d, f). The measurement was performed during EARLI09 on 25 May 2009, 21:00-23:00 UTC. 
(a)

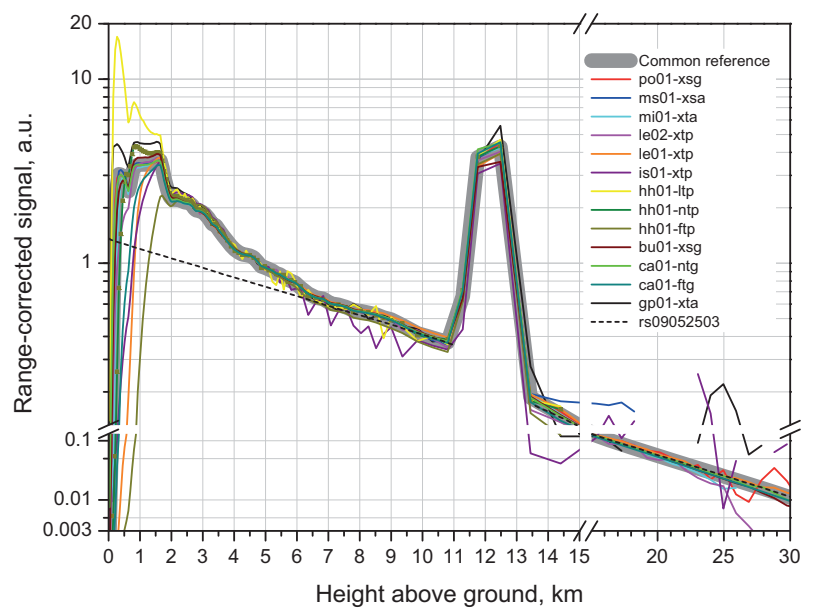

(c)

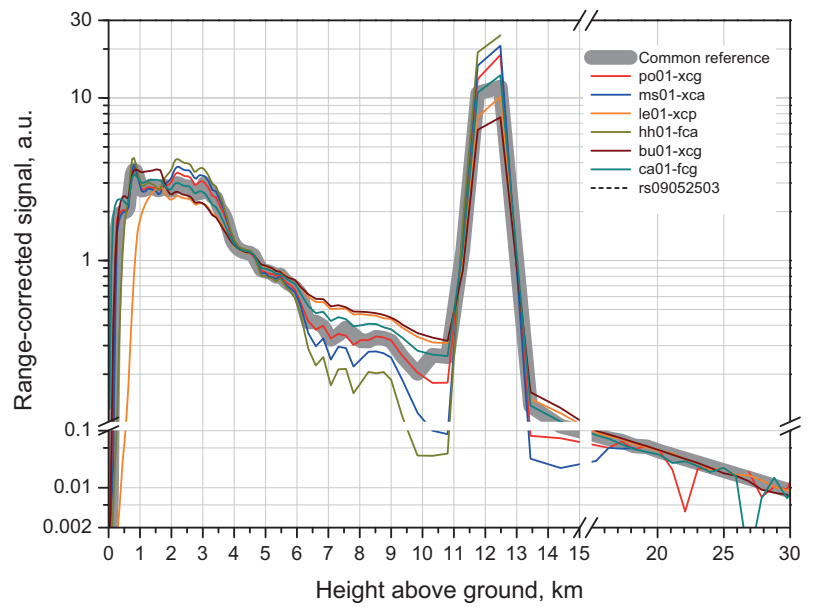

(e)

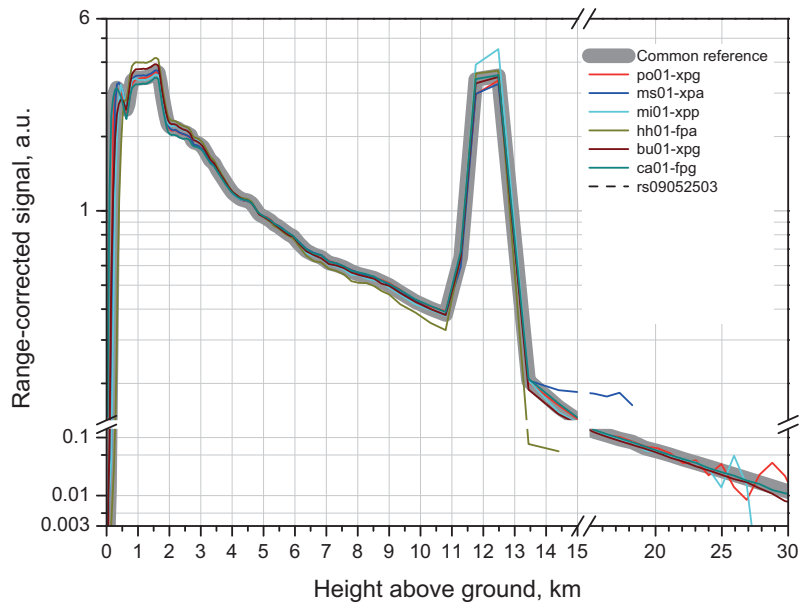

(b)

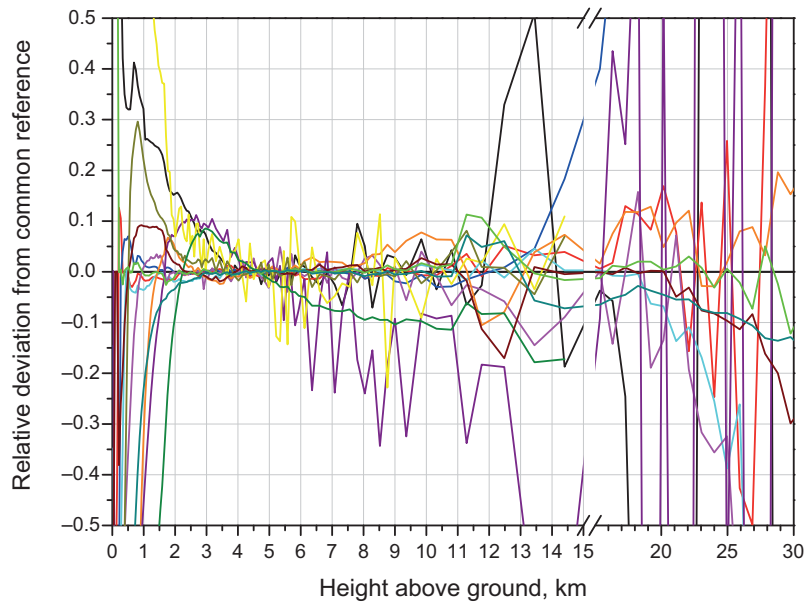

(d)

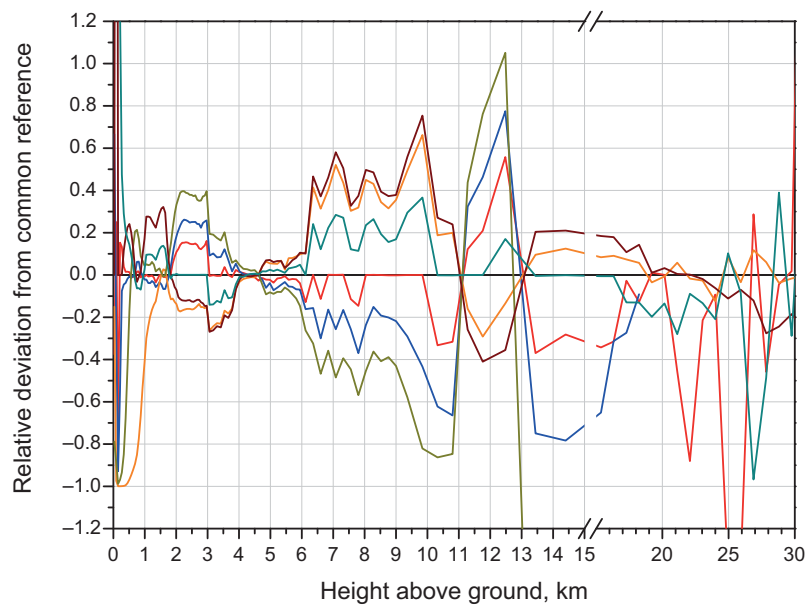

(f)

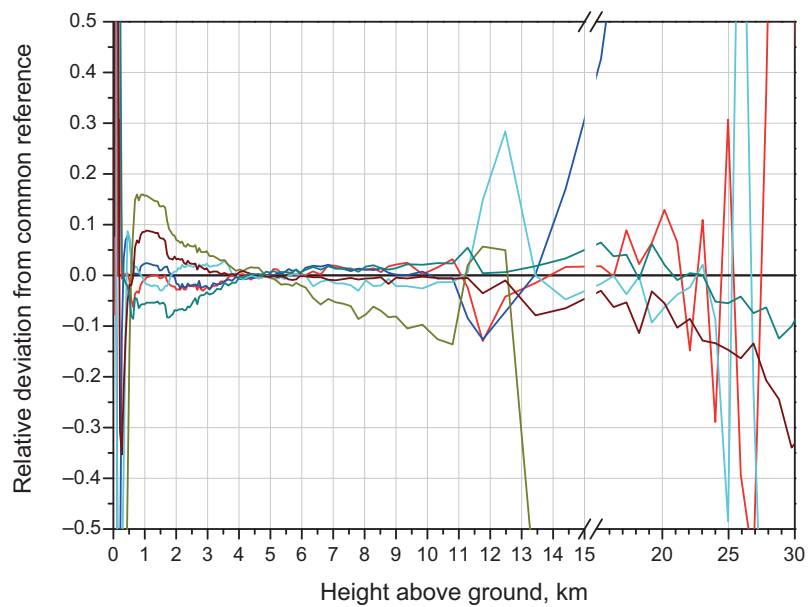

Figure 4. Same as Fig. 3, but for (a, b) total, $(\mathbf{c}, \mathbf{d})$ cross-polarized, and $(\mathbf{e}, \mathbf{f})$ parallel-polarized signals at $532 \mathrm{~nm}$. 
operators were possible, and the lidar could not be validated during the campaign. The reason for the misalignment is a temperature sensitivity of the telescope, which implies defocusing and thus different overlap functions with changing temperature.

Other deviations seen in Figs. 3 and 4 are not considered as major quality deficits, since they are usually known and considered in the data evaluation procedures. For instance, the rotational Raman signals (curves with symbols) deviate because they obtain a larger attenuation than the vibration-rotation signals (due to the shorter wavelength of the backscattered light) and have a temperature dependence. The spread of the $532 \mathrm{~nm}$ cross-polarized signals in Fig. 4c and $d$ is caused by the different suppression of co-polarized radiation due to different polarizers applied in the systems. In this case, the common reference is probably not closest to the truth. The effects are accounted for in the polarization calibration (see Bravo-Aranda et al., 2016 and Belegante et al., 2016). Regarding the somewhat larger deviations within the cirrus cloud, we have to consider that inhomogeneities may influence the signals due to the slightly different pointing of the systems. Nevertheless, polarization-dependent transmission effects are also visible as in the case of the Polly ${ }^{\mathrm{XT}}$ system from Leipzig (le02) at $355 \mathrm{~nm}$ (see Fig. 3a and b). Such effects need to be quantified and corrected for as explained by Mattis et al. (2009) and Freudenthaler (2016).

The results provided for SPALI10 in Tables 3 and 4 are taken from two observational periods on 25 October 2010, 22:15-23:59 UTC (systems ev01, ma01, ba02), and 4 November 2010, 20:00-20:30 UTC (gr01), because an alignment problem of the Granada system (gr01) could be solved only late during the campaign. Nevertheless, the more favorable conditions during the longer measurement period on 25 October 2010 were chosen for the comparison of the other systems. In general, the mean systematic deviations are somewhat larger for SPALI10 than for EARLI09. The campaign suffered from bad weather conditions and thus a limited number of suitable comparison periods. Misalignment errors - which often occur in the beginning of the campaigns, in particular when systems had been transported before could not be completely solved during SPALI10. In the case of the PAOLI system from Évora (ev01; see Tables 3 and 4) the reason for the large deviations in the height ranges $\mathrm{R} 1$ and R2, which are due to a very large range of incomplete overlap, could be identified only when the system was back at Évora. It was found that the field stop was not exactly positioned on the receiver optical axis, possibly because of damage during transport. In addition, it was not possible to obtain successful intercomparisons for all channels during SPALI10. In particular, the signals of the CIEMAT lidar from Madrid (ma01) showed electronic disturbances, varying from day to day, which prevented the Raman channels at 387 and $607 \mathrm{~nm}$ from being verified.

For comparing the Alomar Tropospheric Lidar (an01) with the reference system (hh01) during ALI09, several mea- surement periods on 4 November 2009, between 09:00 and 16:30 UTC, have been investigated. The optical receiver of the Alomar system had been changed considerably before the campaign. It turned out that the setup was not stable throughout the ALI09 campaign. Readjustments were necessary for each session, and it was not possible to obtain a good performance of all channels at the same time. In addition, signal offsets both in analog and photon-counting channels were observed temporarily, which hint to external electronic disturbances in the laboratory environment. From Tables 3 and 4 it can be seen that reasonable agreement with the reference system could be achieved for the 355,387 , and $532 \mathrm{~nm}$ channels up to the mid-troposphere during selected time periods. The $607 \mathrm{~nm}$ signal could not be validated. Consequences are discussed in Sect. 5.

The systems at Sofia were compared during different sessions of SOLI10. Because of the different pointing angles of the lidars, the reference system (mu01) was operated under a zenith angle of $0^{\circ}$ on 10 October 2010, 17:34-17:56 UTC, to compare the sf01 system, and under a zenith angle of $60^{\circ}$ on 10 October 2010, 20:06-20:46 UTC, to compare the sf02 system. Good comparison results were achieved. A minor height shift in the signal of the sf02-system was attributed to a wrong trigger-delay correction. Deviations in the upper troposphere for both systems are due to low signal-to-noise ratios caused by the low system power in the case of sf01 and the large zenith angle in the case of sf02.

The intercomparison period selected for the LALI12 campaign is 15 September 2012, 22:31-23:39 UTC. Excellent performance of the L'Aquila UV lidar (la01) was obtained. Mean systematic deviations from the signals of the reference system (mu01) were $\leq 2 \%$ throughout the entire observational range (see Table 3 ).

For NALI13, the selected measurement period to calculate the numbers presented in Tables 3 and 4 is $17-18$ October 2013, 23:03-00:06 UTC. The MALIA system (na01) compared very well to the reference system (po01), and no significant deviations in any of the channels were obtained.

The Lecce system (1c01) was compared to the reference system (po01) during LELI13 on 22 October 2013, 19:0120:01 UTC. In principle, also here the results were satisfactory. Some smaller biases were identified in the near range and attributed to geometrical effects due to focussing of the signals onto the photocathodes. Further discussion of system deficiencies found in all campaigns and proposed solutions is provided in Sect. 5 .

\subsection{Comparisons at product level}

Figures 5 and 6 show comparison results for particle extinction and backscatter coefficients at 355 and $532 \mathrm{~nm}$, respectively, for the EARLI09 session of 25 May 2009, 21:00-23:00 UTC, derived from the signals presented in Figs. 3 and 4. Particle extinction coefficients were calculated after the Raman method (Ansmann et al., 1990) from 
(a)

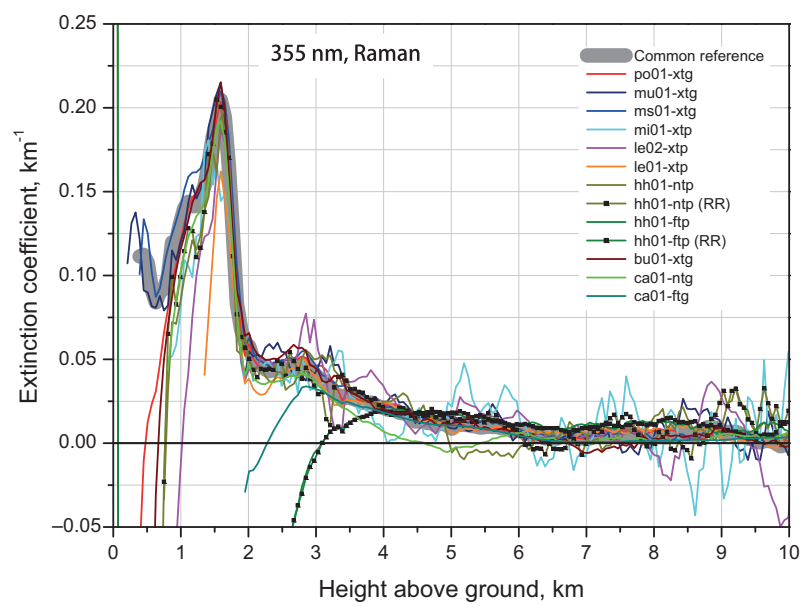

(c)

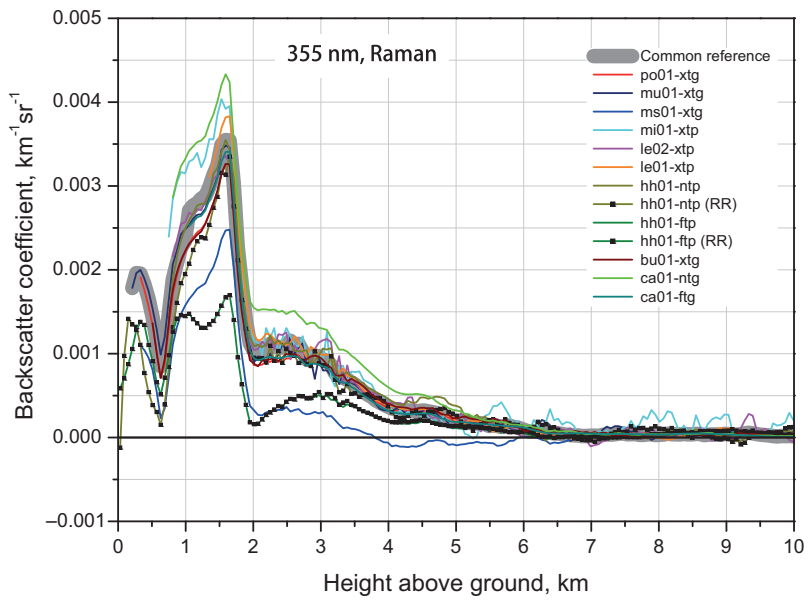

(e)

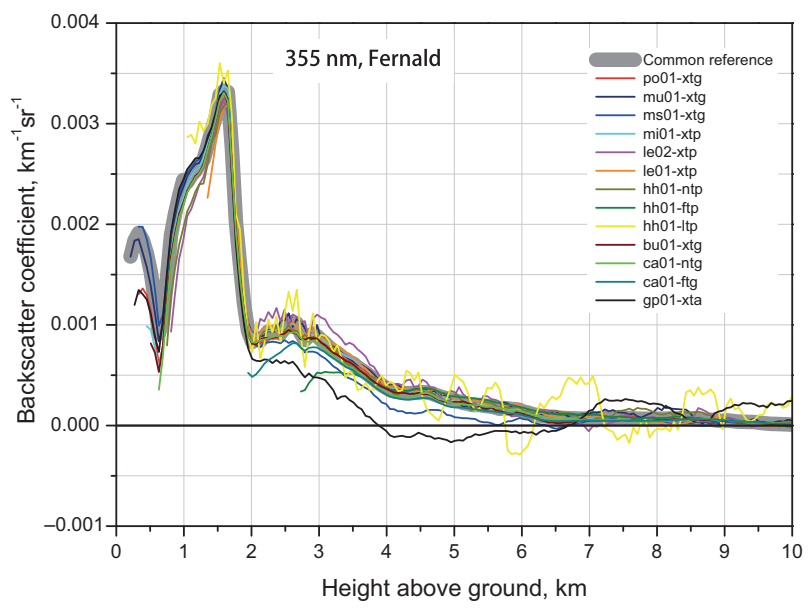

(b)

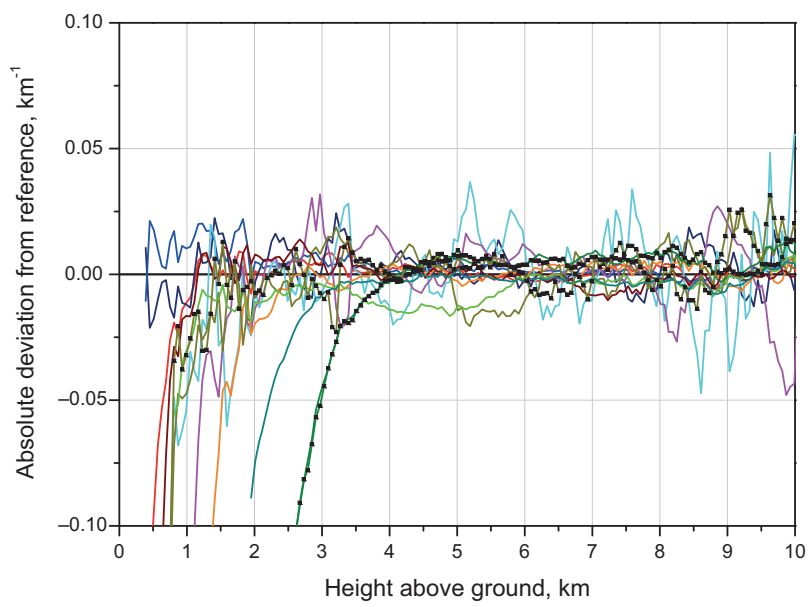

(d)

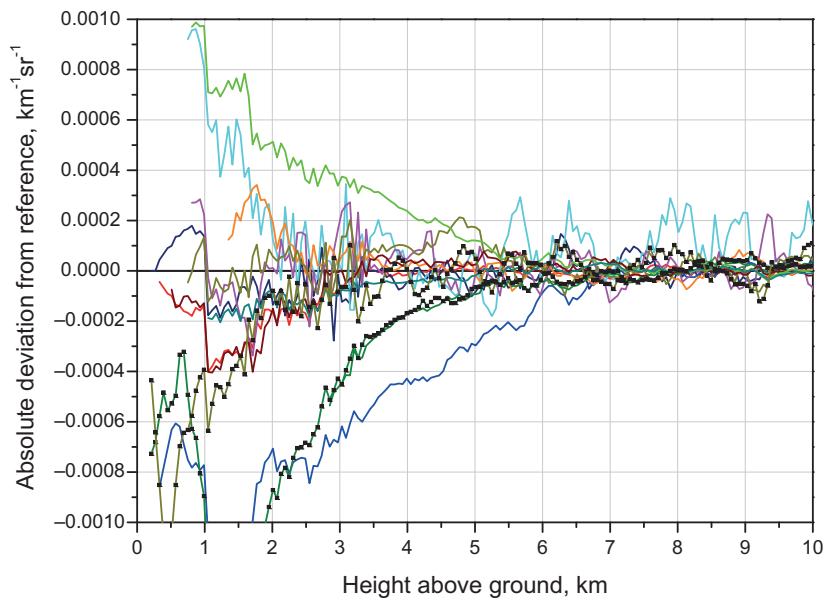

(f)

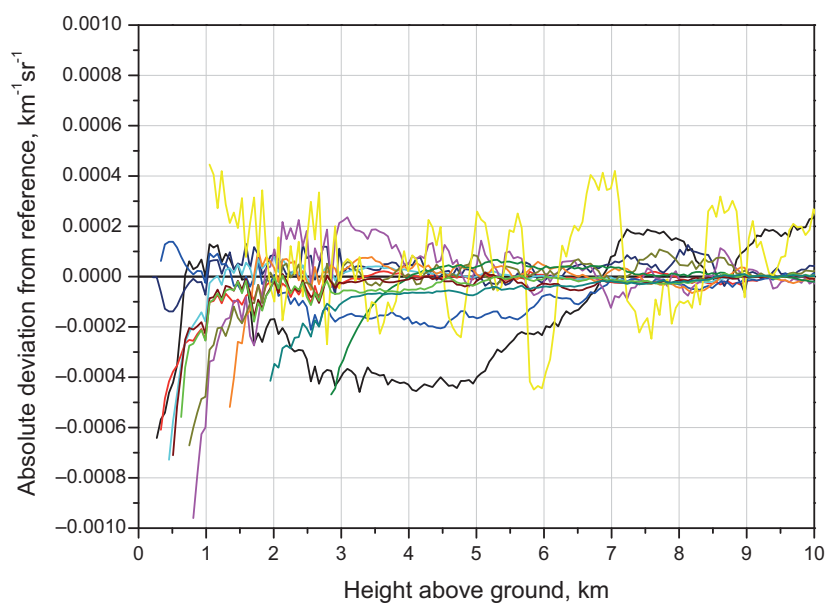

Figure 5. Comparison of particle extinction coefficients (a) and particle backscatter coefficients derived using the Raman (c) and Fernald methods (e), respectively, at $355 \mathrm{~nm}$ and their absolute deviations from the common reference (b, d, e). The measurement was performed during EARLI09 on 25 May 2009, 21:00-23:00 UTC. 
Table 5. Valid range and mean systematic deviation of particle extinction coefficients at 355 and $532 \mathrm{~nm}$ in four height ranges: R1 (lowest valid range-2.5 km), R2 (2.5-6 km), R3 (6-12 km), and R4 (12 km-highest valid range). n.v. denotes not valid. Rec. denotes receiver range.

\begin{tabular}{|c|c|c|c|c|c|c|c|c|c|c|c|}
\hline \multirow[t]{2}{*}{ Lidar } & \multirow[t]{2}{*}{ Rec. } & \multirow[t]{2}{*}{$\begin{array}{l}\text { Valid } \\
\text { range, } \\
\mathrm{km}\end{array}$} & \multicolumn{4}{|c|}{$\begin{array}{c}\text { Mean systematic deviation, } \\
10^{-3} \mathrm{~km}^{-1}, 355 \mathrm{~nm} \text { extinction } \\
\text { coefficient }\end{array}$} & \multirow[t]{2}{*}{$\begin{array}{l}\text { Valid } \\
\text { range, } \\
\mathrm{km}\end{array}$} & \multicolumn{4}{|c|}{$\begin{array}{c}\text { Mean systematic deviation, } \\
10^{-3} \mathrm{~km}^{-1}, 532 \mathrm{~nm} \text { extinction } \\
\text { coefficient }\end{array}$} \\
\hline & & & $\mathrm{R} 1$ & $\mathrm{R} 2$ & $\mathrm{R} 3$ & $\mathrm{R} 4$ & & $\mathrm{R} 1$ & $\mathrm{R} 2$ & $\mathrm{R} 3$ & $\mathrm{R} 4$ \\
\hline \multirow[t]{2}{*}{ hh01 } & far & $3.6-11.3$ & n.v. & +2.6 & +5.9 & n.v. & - & n.v. & n.v. & n.v. & n.v. \\
\hline & near & $1.5-11.3$ & -7.1 & -1.1 & +1.4 & n.v. & $1.2-11.3$ & -6.5 & +0.2 & +2.9 & n.v. \\
\hline ms01 & far & $0.4-16.5$ & +9.5 & +3.6 & -0.6 & +4.7 & $0.8-16.5$ & -7.6 & +0.8 & +0.1 & +6.4 \\
\hline mu01 & & $0.4-14.5$ & +0.6 & +3.6 & +3.0 & -5.1 & - & - & - & - & - \\
\hline po01 & & $0.8-17.5$ & +1.1 & +1.8 & -0.4 & +3.5 & $0.8-11.3$ & +1.8 & +6.7 & +8.3 & n.v. \\
\hline mi01 & & $1.2-10.0$ & -13.0 & +3.5 & +0.3 & n.v. & $1.0-11.3$ & -17.0 & -4.3 & +8.5 & n.v. \\
\hline le01 & & $1.9-20.0$ & -13.0 & -0.3 & +0.4 & +0.6 & $3.0-22.5$ & n.v. & -4.8 & +0.9 & +2.3 \\
\hline le02 & & $1.7-15.0$ & -1.9 & +6.1 & +0.8 & +7.8 & $1.7-15.0$ & -1.4 & +3.9 & +2.1 & +5.8 \\
\hline bu01 & & $1.1-22.0$ & +4.7 & +2.4 & -2.1 & +5.8 & $1.0-15.0$ & +14.0 & +12.0 & -2.6 & -1.6 \\
\hline gp01 & & - & - & - & - & - & $2.5-10.8$ & n.v. & +2.0 & -0.3 & n.v. \\
\hline \multirow[t]{2}{*}{$\mathrm{ca} 01$} & far & $2.9-22.0$ & n.v. & -2.5 & -1.8 & +2.5 & $2.6-22.0$ & n.v. & -2.8 & -1.5 & +0.8 \\
\hline & near & $1.2-22.0$ & -10.0 & -9.6 & -2.0 & +3.9 & $0.6-11.3$ & -8.3 & -4.5 & -3.7 & n.v. \\
\hline gr01 & & $1.0-14.0$ & +8.1 & +1.1 & +16.0 & +24.0 & $1.5-10.0$ & +0.3 & -6.2 & -8.2 & n.v. \\
\hline ev01 & & $2.3-15.0$ & +9.3 & +6.6 & +2.4 & +1.9 & $1.5-8.0$ & +5.9 & -3.0 & +24.0 & n.v. \\
\hline ma01 & & - & n.v. & n.v. & n.v. & n.v. & - & n.v. & n.v. & n.v. & n.v. \\
\hline ba02 & & $1.0-13.0$ & +3.2 & +5.7 & +0.3 & +8.9 & $1.2-6.0$ & -14.0 & -19.0 & n.v. & n.v. \\
\hline $\mathrm{la} 01^{*}$ & & $0.5-13.0$ & +7.5 & +2.1 & +2.1 & +5.6 & - & - & 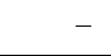 & - & - \\
\hline na01 & & $1.6-14.0$ & -4.3 & +1.9 & +0.8 & +6.7 & $1.5-8.0$ & -6.4 & +9.3 & -0.1 & n.v. \\
\hline lc01 & & $1.0-8.0$ & -3.8 & -1.6 & -1.2 & n.v. & $0.9-6.0$ & -11.0 & -1.9 & n.v. & n.v. \\
\hline
\end{tabular}

* XeF excimer laser; the wavelength is $351 \mathrm{~nm}$.

vibration-rotation Raman signals at 387 and $607 \mathrm{~nm}$, respectively, or from HSRL Rayleigh and rotational Raman signals if available. In the latter case, the two temperaturedependent signals were added in order to get a profile that is nearly temperature-independent. Particle backscatter coefficients were calculated using both the Raman (Ansmann et al., 1992) and the Fernald methods (Fernald, 1984). The reference height range is $7-10 \mathrm{~km}$ for the Raman solutions and $9.4-10 \mathrm{~km}$ for the Fernald solutions. The profiles were calibrated in these height ranges to mean values of $4 \times 10^{-5}$ and $2.5 \times 10^{-5} \mathrm{~km}^{-1} \mathrm{sr}^{-1}$ at 355 and $532 \mathrm{~nm}$, respectively. A lidar ratio of $55 \mathrm{sr}$ was chosen in the Fernald algorithm. A gliding average with increasing window length over height was applied in both extinction and backscatter retrievals. For extinction, the window length increases from $180 \mathrm{~m}$ below $1 \mathrm{~km}$ height to $2.7 \mathrm{~km}$ in the stratosphere. For backscatter, the resolution is $60 \mathrm{~m}$ up to $3.4 \mathrm{~km}$ and increases to $2.7 \mathrm{~km}$ in the stratosphere. All retrievals and comparisons were done without any correction of the individual overlap function.

Tables 5 and 6 show the valid range and the mean absolute deviations from the reference of particle extinction and backscatter coefficients, respectively, for the predefined height ranges for all comparison campaigns. For the backscatter coefficients, the Raman solutions are considered whenever possible. Otherwise, the Fernald solutions are used (italic numbers in the table). Profiles are considered to be valid when they systematically deviate from the reference by $<0.01 \mathrm{~km}^{-1}$ at the low end and by $<0.025 \mathrm{~km}^{-1}$ at the far end of the profile in the case of extinction. For the backscatter coefficients, the limit is set to $3 \times 10^{-4} \mathrm{~km}^{-1} \mathrm{sr}^{-1}$ at both ends. These values are of the order of the statistical measurement errors (see fluctuation of the deviations in the right panels of Figs. 5 and 6) and typically about 10-20\% of the particle extinction and backscatter coefficients measured in distinct aerosol layers (see left panels of Figs. 5 and 6). If cirrus clouds were present, e.g., in the case of the EARLI09 example, these height ranges were excluded from the averages in Tables 5 and 6 because of the heterogeneity of the products due to different measurement geometry. Because of different pointing and various fields of view, not only different volumes are detected, but also the influence of specular reflection and multiple scattering on the products varies from instrument to instrument.

Extinction retrievals (see Figs. 5a, b and 6a, b) clearly show the influence of the different overlap functions. The curves are cut at the lower valid range defined for Raman signals from which they were derived (see Table 3). The lower valid range for the particle extinction coefficient is clearly 
(a)

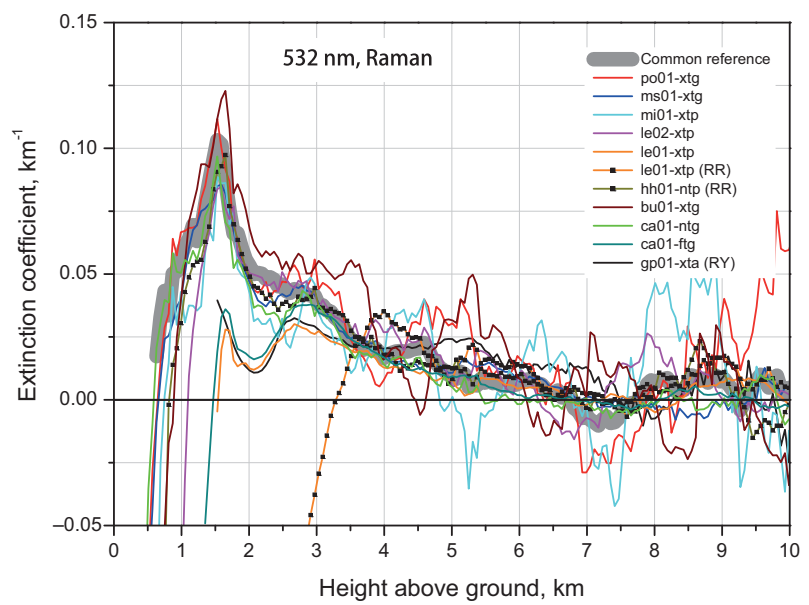

(c)

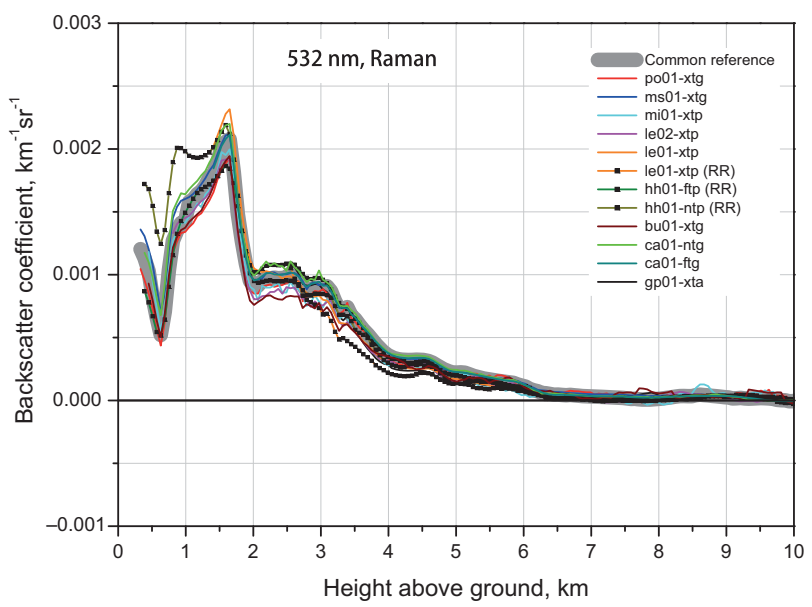

(e)

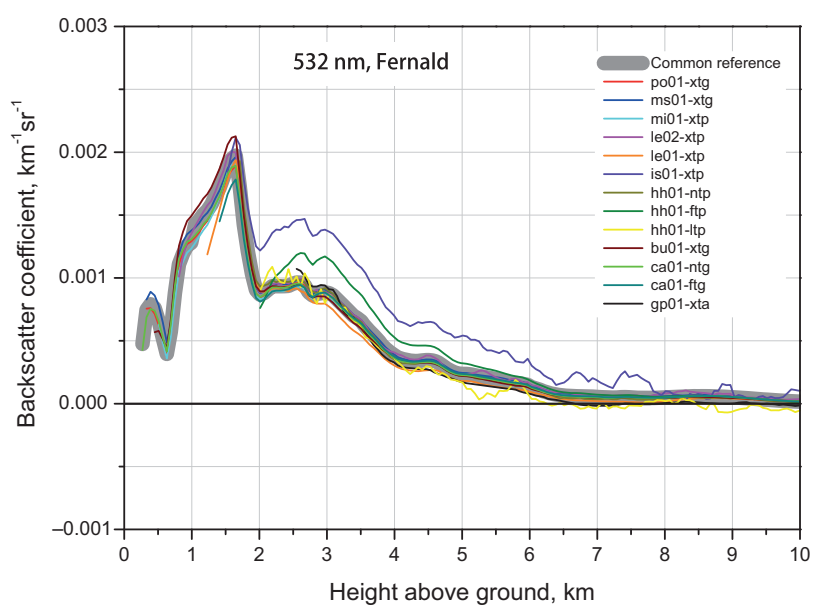

Figure 6. Same as Fig. 5, but for $532 \mathrm{~nm}$. (b)

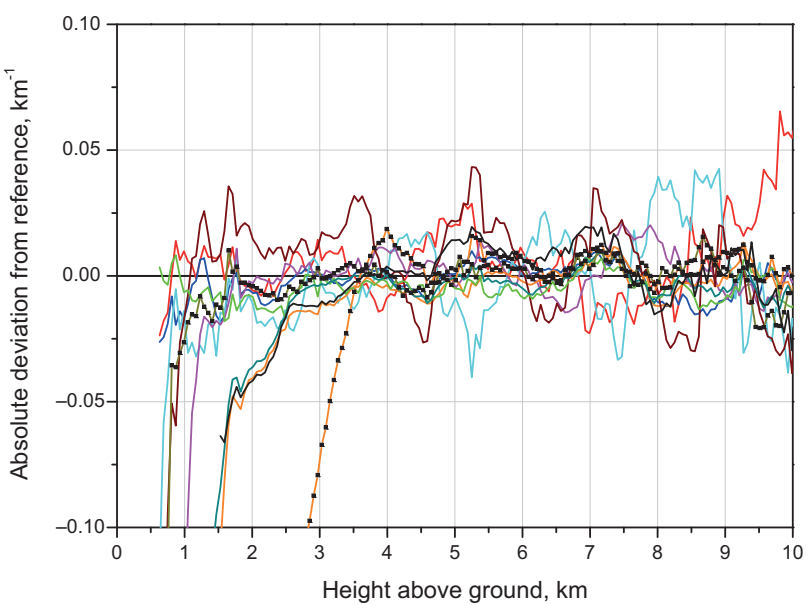

(d)

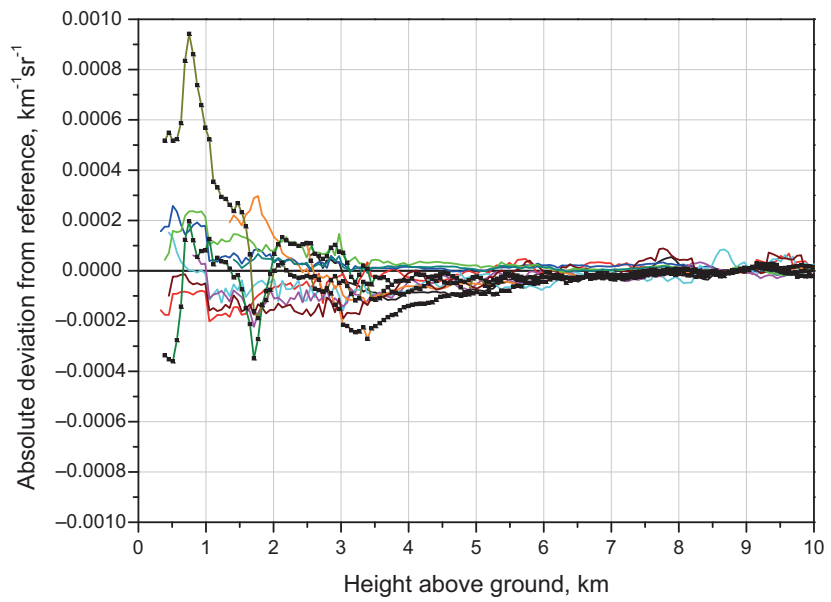

(f)

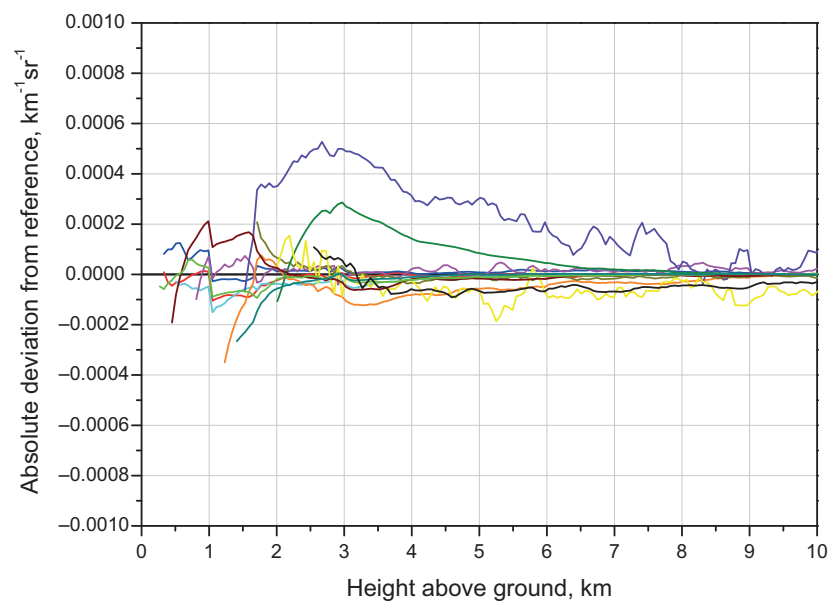


Table 6. Valid range and mean systematic deviation of backscatter coefficients at 355 and $532 \mathrm{~nm}$ in four height ranges: R1 (lowest valid range-2.5 km), R2 (2.5-6 km), R3 (6-12 km), and R4 (12 km-highest valid range). Italicized numbers indicate Fernald retrievals; all other numbers belong to the Raman method. n.v. denotes not valid. Rec. denotes receiver range.

\begin{tabular}{|c|c|c|c|c|c|c|c|c|c|c|c|}
\hline \multirow[t]{2}{*}{ Lidar } & \multirow[t]{2}{*}{ Rec. } & \multirow[t]{2}{*}{$\begin{array}{l}\text { Valid } \\
\text { range, } \\
\mathrm{km}\end{array}$} & \multicolumn{4}{|c|}{$\begin{array}{c}\text { Mean systematic deviation, } \\
10^{-5} \mathrm{~km}^{-1} \mathrm{sr}^{-1}, 355 \mathrm{~nm} \text { backscatter } \\
\text { coefficient }\end{array}$} & \multirow[t]{2}{*}{$\begin{array}{l}\text { Valid } \\
\text { range, } \\
\mathrm{km}\end{array}$} & \multicolumn{4}{|c|}{$\begin{array}{c}\text { Mean systematic deviation, } \\
10^{-5} \mathrm{~km}^{-1} \mathrm{sr}^{-1}, 532 \mathrm{~nm} \text { backscatter } \\
\text { coefficient }\end{array}$} \\
\hline & & & $\mathrm{R} 1$ & $\mathrm{R} 2$ & R3 & $\mathrm{R} 4$ & & $\mathrm{R} 1$ & $\mathrm{R} 2$ & $\mathrm{R} 3$ & $\mathrm{R} 4$ \\
\hline \multirow[t]{2}{*}{ hh01 } & far & $3.5-13.4$ & n.v. & -12.0 & +0.1 & +4.6 & - & - & - & - & - \\
\hline & near & $0.7-13.4$ & +0.1 & +7.6 & +1.7 & +1.4 & - & - & - & - & - \\
\hline $\mathrm{ms} 01$ & far & $0.3-11.3$ & -85.0 & -42.0 & -0.1 & n.v. & $0.3-17.0$ & +9.3 & +1.3 & +0.7 & -12.0 \\
\hline $\mathrm{mu} 01$ & & $0.3-19.0$ & -3.0 & -3.3 & +0.7 & +5.0 & - & - & - & - & - \\
\hline po01 & & $0.3-30.0$ & -21.0 & -1.8 & +0.2 & +6.6 & $0.3-30.0$ & -11.0 & -1.6 & +3.4 & -14.0 \\
\hline mi01 & & $0.8-10.0$ & +40.0 & +3.7 & +10.0 & n.v. & $0.5-11.0$ & -4.2 & -6.5 & +0.6 & n.v. \\
\hline le01 & & $1.3-28.0$ & +18.0 & +2.3 & -0.1 & +5.3 & $1.3-30.0$ & +15.0 & -6.4 & -0.8 & +0.6 \\
\hline le02 & & $0.8-17.0$ & -0.5 & +2.4 & +1.5 & +9.7 & $0.8-15.0$ & -9.4 & -6.4 & -1.2 & -1.5 \\
\hline is 01 & & - & - & - & - & - & $(1.5-11.5)$ & +34.0 & +33.0 & +7.3 & n.v. \\
\hline bu01 & & $0.5-30.0$ & -22.0 & +1.6 & -0.1 & +2.5 & $0.5-15.0$ & -12.0 & -6.7 & +1.1 & +4.9 \\
\hline gp01 & & $0.6-2.5$ & -9.0 & n.v. & n.v. & n.v. & $2.5-11.3$ & n.v. & -5.5 & -0.4 & n.v. \\
\hline \multirow[t]{2}{*}{$\mathrm{ca} 01$} & far & $1.0-30.0$ & -14.0 & -4.2 & +0.6 & -0.1 & $1.4-27.0$ & +3.8 & +1.5 & +0.4 & -0.6 \\
\hline & near & $0.8-28.0$ & +64.0 & +21.0 & +1.4 & +0.1 & $0.4-30.0$ & +13.0 & +3.6 & +0.7 & -5.2 \\
\hline gr01 & & $0.7-30.0$ & -2.6 & -0.3 & -6.3 & -4.0 & $0.4-15.0$ & +4.7 & +0.0 & -1.8 & -5.7 \\
\hline ev01 & & $0.2-25.0$ & +13.0 & +2.3 & +0.0 & +6.9 & $0.2-14.0$ & -2.2 & +0.9 & -4.0 & +17.0 \\
\hline $\mathrm{ma01}$ & & $1.0-8.0$ & -0.5 & +2.1 & -13.0 & n.v. & $0.3-25.0$ & -3.0 & -0.7 & -0.2 & -0.3 \\
\hline ba02 & & $0.5-28.0$ & +0.1 & +5.2 & -0.6 & +3.2 & $0.2-14.0$ & -2.2 & +0.9 & -2.7 & +19.0 \\
\hline $\mathrm{sf} 01^{\mathrm{a}}$ & & - & - & - & - & - & $1.5-10.0$ & +14.0 & +3.6 & +1.0 & n.v. \\
\hline sf02 & & - & - & - & - & - & $0.5-12.0$ & -0.7 & +5.6 & +2.2 & n.v. \\
\hline $\mathrm{la} 01^{\mathrm{b}}$ & & $0.2-13.0$ & +8.5 & +0.2 & -6.3 & -0.3 & - & - & - & - & - \\
\hline na01 & & $0.9-18.0$ & +12.0 & +2.8 & +0.7 & +6.7 & $0.7-12.0$ & +6.6 & +1.5 & -2.3 & n.v. \\
\hline lc01 & & $0.8-13.0$ & +13.0 & +5.2 & +2.0 & +8.2 & $1.0-12.0$ & +12.0 & +0.1 & -1.3 & n.v. \\
\hline
\end{tabular}

${ }^{\text {a }} \mathrm{CuBr}$ laser; the wavelength is $510 \mathrm{~nm}$,

${ }^{\mathrm{b}} \mathrm{XeF}$ excimer laser; the wavelength is $351 \mathrm{~nm}$.

higher and above $0.8 \mathrm{~km}$ for most systems, even when the receiver is optimized for the near range. When complete overlap is reached, the mean systematic deviations of the particle extinction coefficients are small and typically well below $\pm 0.01 \mathrm{~km}^{-1}$ throughout the troposphere. Signal noise is the dominating source of uncertainty then, in particular at $532 \mathrm{~nm}$ above $3-4 \mathrm{~km}$ height, where several curves show large fluctuations (see Fig. 6a, e.g., mi01, bu01).

Backscatter coefficients can be derived closer towards the ground than extinction coefficients. In the Raman retrieval the overlap effect cancels out when both the elasticbackscatter signal and the Raman signal have the same geometrical overlap function. However, since differences in optical imaging and signal nonlinearities may occur in the near range, this compensation does not work in all cases, as can be seen from Figs. 5c, d and 6c, d. Another reason for the spread of the curves towards the ground is the identical calibration in a common reference range. When the signals are disturbed in this range, the calibration fails and the whole profile is corrupted. For instance, the particle backscatter co- efficient at $355 \mathrm{~nm}$ of the MULIS system (ms01) is shifted towards values that are too low because of an analog signal distortion (positive offset) in the calibration range (7-10 km).

The Fernald solutions for the particle backscatter coefficients at 355 and $532 \mathrm{~nm}$ are shown in Figs. 5e, f and 6e, f, respectively. The curves are cut at the lower end according to the valid range of the elastic-backscatter signals provided in Tables 3 and 4, i.e., when the relative signal deviation from the reference becomes $>10 \%$. It can be seen that close to this lower boundary, the particle backscatter coefficients are derived with an acceptable absolute deviation of $<7 \times 10^{-4}$ and $<3 \times 10^{-4} \mathrm{~km}^{-1} \mathrm{sr}^{-1}$ at 355 and $532 \mathrm{~nm}$, respectively. Analog signal distortions in the reference range lead to offsets here as well (see, e.g., gp01 in Fig. 5e, f). In Fig. $6 e, f$ the result of the retrieval for the CAML lidar from Ispra (is01) is also shown. The misalignment discussed above leads to a bias of up to $5 \times 10^{-4} \mathrm{~km}^{-1} \mathrm{sr}^{-1}$ in the free troposphere. Beside those few exceptions, for which the reasons could be identified, the mean systematic deviation of the particle backscatter coefficients, from Raman as well as Fernald 
retrievals, is $<2 \times 10^{-4} \mathrm{~km}^{-1} \mathrm{sr}^{-1}$ above the defined minimum valid range (see Table 6).

\section{Discussion}

The EARLINET intercomparisons performed between 2009 and 2013 provided a broad insight into the level of quality that has been reached in the network after nearly 15 years of operation. The decision to perform comparisons not only at product level as done before (Matthias et al., 2004) but also at signal level, based on a common preprocessing, allowed for a much deeper analysis of individual measurement channels and potential system failures. For the majority of the detection channels, mean systematic deviations from the reference over predefined height ranges were below $\pm 1-2 \%$ in the upper PBL and the free troposphere. Particle backscatter and extinction coefficients could then be retrieved with an accuracy of better than $\pm 2 \times 10^{-4} \mathrm{~km}^{-1} \mathrm{sr}^{-1}$ and $\pm 0.01 \mathrm{~km}^{-1}$, respectively. These values are well below the quality margins of $\pm 5 \times 10^{-4} \mathrm{~km}^{-1} \mathrm{sr}^{-1}$ and $\pm 0.05 \mathrm{~km}^{-1}$ defined by Matthias et al. (2004) and of the order of $10 \%$ of typical particle backscatter and extinction values observed in the PBL.

Some of the signals showed higher systematic biases, which were further investigated. Typical reasons were misalignment errors. Such errors were often observed in the beginning of the campaigns, in particular when the systems had been transported before. This finding depicts a shortcoming of centralized intercomparison campaigns for which many systems have to be moved and operated outside of their normal environments. Personnel that are used to working with stationary systems under well-defined conditions usually need some time to gain experience with the challenges of a field campaign. Such problems do not occur when on-site comparisons with a well-characterized traveling standard are performed instead. Some of the systematic biases obtained could be attributed to signal distortions in analog detection channels or problems with the gluing of analog and photoncounting signals due to incorrect setting of acquisition parameters. These facts also call for expert site visits and individual training in order to check systems in their laboratory environment and advise personnel, in particular new network members, in specific quality-checking procedures.

Further shortcomings observed during the intercomparison campaigns, which could not be solved on-site, led to consequences regarding system upgrades or replacement. After the failure of CAML (is01) in the EARLI09 campaign, this system was removed from the network and the station at Ispra was upgraded with a new $3+2$ lidar system manufactured by Raymetrics (even if the performance of CAML could be improved after EARLI09 by operating the lidar at a controlled temperature of $35 \pm 4^{\circ} \mathrm{C}$ ). The new lidar has been in operation at Ispra since March 2013. Several systems with low performance in the PBL have been upgraded with near-range receivers, among them the MARTHA sys- tem from Leipzig (le01). Also, the newest generation of Polly XT lidars (here represented by le02) is equipped with additional channels that allow measurements down to about $50 \mathrm{~m}$ height (Engelmann et al., 2015). In the CIEMAT lidar system (ma01), which suffered from mechanical instability and electronic disturbances in the two Raman channels during SPALI10, the respective PMTs (model Hamamatsu R928) were replaced. The new data acquisition is based on a Licel/Hamamatsu PMT R7400P-20 for the $607 \mathrm{~nm}$ channel and a Licel/Hamamatsu PMT R9880 U-110 for the $387 \mathrm{~nm}$ channel, and combined analog and photon-counting detection is applied. Moreover, mechanical modifications for a better robustness of the system were implemented. After the LELI13 campaign in Lecce, during which some biases in the near range of the UNILE system (lc01) had been detected, the receiver of the multiwavelength lidar at this station was modified and the single focussing lens in front of each detector was replaced with a collimator in order to avoid geometrical effects due to inhomogeneities of the detector surfaces.

Regarding the Alomar Tropospheric Lidar (an01), which showed major deficiencies during ALI09, a number of measures, implemented after discussion with EARLINET experts, resulted in distinct improvements of the system. The electrical noise, induced by the laser, could be reduced by using a fiber coupling to achieve a galvanic separation of the data acquisition electronics and the light source. The cause for the poor quality of the $607 \mathrm{~nm}$ channel was identified as the combination of an interference filter that is too broad and a photomultiplier with poor quantum efficiency at this wavelength. During a system refurbishment, this channel has been removed, the main mirror was recoated, and the crosstalk of the depolarization channels was minimized with additional polarizing sheet filters. In addition, an automated polarization calibration unit was installed (Freudenthaler et al., 2009).

In general, dedicated intercomparison campaigns as discussed in this paper require large efforts and can thus only be performed sporadically. Nevertheless, because of the lack of external calibration standards for aerosol lidar observations, any instrument intercomparison is of great value for quality assurance. Therefore, following the principle of best scientific practice, every opportunity of cross-checking the quality of measurements by a direct comparison of results from collocated observations should be used. Within EARLINET and in collaboration between EARLINET and other research projects, direct instrument intercomparisons are performed whenever possible. Regular intercomparisons take place at sites where more than one system is available, e.g., because the groups own one of the reference systems in addition to their stationary lidar (Potenza, Minsk, Hamburg, Munich/Maisach) or apply other lidars in experiments outside of EARLINET (Leipzig, Naples). Other opportunities are related to dedicated field campaigns in which several lidars often participate. In this context, comparisons with downlook- 
ing airborne lidars may also be used to check the system performance in the near range.

\section{Conclusions and outlook}

In this paper, we have presented results of the EARLINET instrument intercomparison campaigns between 2009 and 2013. During this period, about two-thirds of the EARLINET systems performed comparison measurements with one or more reference systems. In two dedicated campaigns, EARLI09 and SPALI10, 15 instruments underwent this quality-assurance procedure. EARLI09 also served to qualify the reference systems that are used as traveling standards within the network. With these reference instruments, six other systems were checked during direct station visits. Altogether, more than 100 individual measurement channels were examined, based on a common strategy of signal preprocessing and evaluation following the principles of the EARLINET Single Calculus Chain. In most cases, a very good agreement of signals as well as derived aerosol products with the defined reference could be obtained. The intercomparisons have reinforced confidence in the EARLINET data quality and allowed us to draw conclusions on necessary system improvements for some instruments and to identify major challenges that need to be tackled in the future.

EARLINET is a living network that is continuously in development, both regarding the instrument level and the network distribution. Most of the stations regularly upgrade their systems by adding new measurement capabilities based on recent experience, technological developments, and available funding. Thus, a complete assessment of all systems at any time in any specific setup through intercomparison with a reference system is not possible. Therefore, complementary quality-assurance concepts need to be applied. EARLINET requires regular internal system check-ups in addition to the sporadic intercomparisons. Specific internal check-up tools, such as the telecover test for the near range and the Rayleigh fit for the far range, have been developed and must be applied at least once per year as well as after each major system upgrade. These activities are discussed in detail by Freudenthaler et al. (2016).

Within the ACTRIS-2 project, which started in May 2015, the quality-assurance efforts of EARLINET will be further improved. In order to provide a long-term, sustainable infrastructure that can serve the lidar community even beyond EARLINET, the Lidar Calibration Centre, LiCal, will be established. LiCal is a common effort of the EARLINET groups at INOE (Bucharest, Romania), CNR-IMAA (Potenza, Italy), and LMU (Munich, Germany). It will provide lidar calibration services from the characterization and optimization of single components to the assessment of complete systems through intercomparison with reference systems. The POLIS (mu01) and MUSA (po01) reference lidars will be further upgraded and used exclusively for this purpose in the future. LiCal will also host a lidar training laboratory in order to educate station personnel in applying lidar check-up tools and maintaining lidar calibration. In this way, the long-term quality-assurance strategy of EARLINET, which has been successfully established over the past 15 years, will be further consolidated.

Acknowledgements. The financial support for EARLINET-ASOS by the European Commission in the Sixth Framework Programme under grant RICA-025991, for ACTRIS in the Seventh Framework Programme under grant agreement no. 262254, and for ACTRIS-2 in HORIZON 2020 under grant agreement no. 654109, as well as the ESA financial support under the ESRIN contract no. 22202/09/I-EC, are gratefully acknowledged. We thank Julia Fruntke, Christian Herold, and the technical staff of TROPOS for the logistical support, radiosonde launches, and weather forecast during EARLI09, as well as the Atmosphere Group of INTAMadrid for their support with the radiosounding during SPALI10. The Universitat Politècnica de Catalunya wishes to acknowledge the technical and logistic support of Joaquim Giner and Rubén Tardío. The work of the INOE team was supported by grant no. 229907 FP7-REGPOT-2008-1. The Universitat Politècnica de Catalunya group received support from the Spanish Ministry of Economy and Competitiveness (project TEC2012-34575) and of Science and Innovation (project UNPC10-4E-442), as well as from the Department of Economy and Knowledge of the Catalonia autonomous government (grant 2014 SGR 583).

Edited by: R. Ferrare

\section{References}

Althausen, D., Engelmann, R., Baars, H., Heese, B., Ansmann, A., Müller, D., and Komppula, M.: Portable Raman Lidar Polly $\mathrm{XT}$ for automated profiling of aerosol backscatter, extinction, and depolarization, J. Atmos. Ocean. Tech., 26, 2366-2378, doi:10.1175/2009JTECHA1304.1, 2009.

Ansmann, A., Riebesell, M., and Weitkamp, C.: Measurement of atmospheric aerosol extinction profiles with a Raman lidar, Opt Lett., 15, 746-748, doi:10.1364/OL.15.000746, 1990.

Ansmann, A., Riebesell, M., Wandinger, U., Weitkamp, C., Voss, E., Lahmann, W., and Michaelis, W.: Combined Raman elasticbackscatter lidar for vertical profiling of moisture, aerosol extinction, backscatter, and lidar ratio, Appl. Phys. B, 55, 18-28, doi:10.1007/BF00348608, 1992.

Apituley, A., Wilson, K. M., Potma, C., Volten, H., and de Graaf, M.: Performance Assessment and Application of Caeli - A highperformance Raman lidar for diurnal profiling of Water Vapour, Aerosols and Clouds, in: Proceedings of the 8th International Symposium on Tropospheric Profiling, Delft, the Netherlands, 19-23 October 2009, edited by: Apituley, A., Russchenberg, H. W. J., and Monna, W. A. A., ISBN 978-90-6960-233-2, 2009.

Barnaba, F., Putaud, J. P., Gruening, C., dell'Acqua, A., and Dos Santos, S.: Annual cycle in co-located in situ, total-column, and height-resolved aerosol observations in the Po Valley (Italy): Implications for ground-level particulate matter mass concentration 
estimation from remote sensing, J. Geophys. Res., 115, D19209, doi:10.1029/2009JD013002, 2010.

Belegante, L., Nicolae, D., Nemuc, A., Talianu, C. and Derognat, C.: Retrieval of the boundary layer height from active and passive remote sensors. Comparison with a NWP model, Acta Geophys., 62, 276-289, doi:10.2478/s11600-013-0167-4, 2014.

Belegante, L., Bravo-Aranda, J. A., Freudenthaler, V., Nicolae, D., Nemuc, A., Alados-Arboledas, L., Amodeo, A., Pappalardo, G., D’Amico, G., Engelmann, R., Baars, H., Wandinger, U., Papayannis, A., Kokkalis, P., and Pereira, S. N.: Experimental assessment of the lidar polarizing sensitivity, Atmos. Meas. Tech. Discuss., doi:10.5194/amt-2015-337, in review, 2016.

Böckmann, C., Wandinger, U., Ansmann, A., Bösenberg, J., Amiridis, V., Boselli, A., Delaval, A., De Tomasi, F., Frioud, M., Hågård, A., Horvat, M., Iarlori, M., Komguem, L., Kreipl, S., Larchevêque, G., Matthias, V., Papayannis, A., Pappalardo, G., Rocadembosch, F., Rodriguez, J. A., Schneider, J., Shcherbakov, V., and Wiegner, M.: Aerosol lidar intercomparison in the framework of the EARLINET project. 2. Aerosol backscatter algorithms, Appl. Opt., 43, 977-989, doi:10.1364/AO.43.000977, 2004.

Böckmann, C., Mironova, I., Müller, D., Scheidenbach, L., and Nessler, R.: Microphysical aerosol parameters from multiwavelength lidar, J. Opt. Soc. Am. A, 22, 518-528, doi:10.1364/JOSAA.22.000518, 2005.

Bravo-Aranda, J. A., Belegante, L., Freudenthaler, V., AladosArboledas, A., Nicolae, D., Granados-Muñoz, M. J., GuerreroRascado, J. L., Amodeo, A., D’Amico, G., Engelmann, R., Pappalardo, G., Kokkalis, P., Mamouri, R., Papayannis, A., NavasGuzmán, F., Olmo, F. J., Wandinger, U., and Haeffelin, M.: Assessment of lidar depolarization uncertainty by means of a polarimetric lidar simulator, Atmos. Meas. Tech. Discuss., doi:10.5194/amt-2015-339, in review, 2016.

D’Amico, G., Amodeo, A., Baars, H., Binietoglou, I., Freudenthaler, V., Mattis, I., Wandinger, U., and Pappalardo, G.: EARLINET Single Calculus Chain - overview on methodology and strategy, Atmos. Meas. Tech., 8, 4891-4916, doi:10.5194/amt-84891-2015, 2015.

D'Amico, G., Amodeo, A., Mattis, I., Freudenthaler, V., and Pappalardo, G.: EARLINET Single Calculus Chain - technical - Part 1: Pre-processing of raw lidar data, Atmos. Meas. Tech., 9, 491507, doi:10.5194/amt-9-491-2016, 2016.

Engelmann, R., Kanitz, T., Baars, H., Heese, B., Althausen, D., Skupin, A., Wandinger, U., Komppula, M., Stachlewska, I. S., Amiridis, V., Marinou, E., Mattis, I., Linné, H., and Ansmann, A.: EARLINET Raman Lidar PollyXT: the neXT generation, Atmos. Meas. Tech. Discuss., 8, 7737-7780, doi:10.5194/amtd-87737-2015, 2015.

Engelmann, R., Guerrero-Rascado, J. L., Alados-Arboledas, L., Wandinger, U., Freudenthaler, V., Baars, H., Mattis, I., Groß, S., Pappalardo, G., Amodeo, A., D’Amico, G., Giunta, A., Chaikovsky, A., Osipenko, F., Slesar, A., Nicolae, D., Belegante, L., Serikov, I., Linné, H., Jansen, F., Apituley, A., Wilson, K., Trickl, T., and Rocadenbosch, F.: Calibrated backscatter measurements at $1064 \mathrm{~nm}$ with lidar: Techniques used in EARLINET and ACTRIS, Atmos. Meas. Tech. Discuss., in preparation, 2016.

Fernald, F. G.: Analysis of atmospheric lidar observations: some comments, Appl. Opt., 23, 652-653, doi:10.1364/AO.23.000652, 1984.
Freudenthaler, V.: About the effects of polarising optics on lidar signals and the $\Delta 90$-calibration, Atmos. Meas. Tech. Discuss., doi:10.5194/amt-2015-338, in review, 2016.

Freudenthaler, V., Esselborn, M., Wiegner, M., Heese, B., Tesche, M., Ansmann, A., Müller, D., Althausen, D., Wirth, M., Fix, A., Ehret, G., Knippertz, P., Toledano, C., Gasteiger, J., Garhammer, M., and Seefeldner, M.: Depolarization ratio profiling at several wavelengths in pure Saharan dust during SAMUM 2006, Tellus B, 61, 165-179, doi:10.1111/j.1600-0889.2008.00396.x, 2009.

Freudenthaler, V., Linné, H., Chaikovsky, A., Groß, S., and Rabus, D.: Internal quality assurance tools, Atmos. Meas. Tech. Discuss., in preparation, 2016.

Freudenthaler, V., Seefeldner, M., Groß, S., and Wandinger, U.: Accuracy of linear depolarisation ratios in clean air ranges measured with POLIS-6 at 355 and 532 nm, 27th International Laser Radar Conference, 6-10 July 2015, New York City, USA, available at: http://epub.ub.uni-muenchen.de/24942/ (last access: 18 February 2016), 2015.

Guerrero-Rascado, J. L., Ruiz, B., and Alados-Arboledas, L.: Multispectral Lidar characterization of the vertical structure of Saharan dust aerosol over Southern Spain, Atmos. Environ., 42, 2668-2681, doi:10.1016/j.atmosenv.2007.12.062, 2008.

Guerrero-Rascado, J. L., Olmo, F. J., Avilés-Rodríguez, I., NavasGuzmán, F., Pérez-Ramírez, D., Lyamani, H., and Alados Arboledas, L.: Extreme Saharan dust event over the southern Iberian Peninsula in september 2007: active and passive remote sensing from surface and satellite, Atmos. Chem. Phys., 9, 84538469, doi:10.5194/acp-9-8453-2009, 2009.

Kumar, D., Rocadenbosch, F., Sicard, M., Comerón, A., Muñoz, C., Lange, D., Tomás, S., and Gregorio, E.: Six-channel polychromator design and implementation for the UPC elastic/Raman lidar, in: Proc. of SPIE, Vol. 8182, edited by: Singh, U. N. and Pappalardo, G., pp. 81820W-1-81820W-10, International Society for Optics and Photonics, doi:10.1117/12.896305, 2011.

Leblanc, T., Walsh, T. D., McDermid, I. S., Toon, G. C., Blavier, J.-F., Haines, B., Read, W. G., Herman, B., Fetzer, E., Sander, S., Pongetti, T., Whiteman, D. N., McGee, T. G., Twigg, L., Sumnicht, G., Venable, D., Calhoun, M., Dirisu, A., Hurst, D., Jordan, A., Hall, E., Miloshevich, L., Vömel, H., Straub, C., Kampfer, N., Nedoluha, G. E., Gomez, R. M., Holub, K., Gutman, S., Braun, J., Vanhove, T., Stiller, G., and Hauchecorne, A.: Measurements of Humidity in the Atmosphere and Validation Experiments (MOHAVE)-2009: overview of campaign operations and results, Atmos. Meas. Tech., 4, 2579-2605, doi:10.5194/amt-42579-2011, 2011.

Madonna, F., Amodeo, A., Boselli, A., Cornacchia, C., Cuomo, V., D’Amico, G., Giunta, A., Mona, L., and Pappalardo, G.: CIAO: the CNR-IMAA advanced observatory for atmospheric research, Atmos. Meas. Tech., 4, 1191-1208, doi:10.5194/amt4-1191-2011, 2011.

Matthias, V., Freudenthaler, V., Amodeo, A., Balin, I., Balis, D., Bösenberg, J., Chaikovsky, A., Chourdakis, G., Comeron, A., Delaval, A., De Tomasi, F., Eixmann, R., Hågård, A., Komguem, L., Kreipl, S., Matthey, R., Rizi, V., Rodrigues, J., Wandinger, U., and Wang, X.: Aerosol lidar intercomparison in the framework of the EARLINET project. 1. Instruments, Appl. Opt., 43, 961-976, doi:10.1364/AO.43.000961, 2004. 
Mattis, I., Ansmann, A., Müller, D., Wandinger, U., and Althausen, D.: Multiyear aerosol observations with dual-wavelength Raman lidar in the framework of EARLINET, J. Geophys. Res., 109, D13203, doi:10.1029/2004JD004600, 2004.

Mattis, I., Ansmann, A., Müller, D., Wandinger, U., and Althausen, D.: Systematic error of lidar profiles caused by a polarization-dependent receiver transmission: Quantification and error correction scheme, Appl. Opt., 48, 2742-2751, doi:10.1364/AO.48.002742, 2009.

Mattis, I., D’Amico, G., Baars, H., Amodeo, A., Madonna, F., and Ialori, M.: EARLINET Single Calculus Chain - technical - Part 2: Calculations of optical products, Atmos. Meas. Tech. Discuss., submitted, 2016.

Müller, D., Wandinger, U., and Ansmann, A.: Microphysical particle parameters from extinction and backscatter lidar data by inversion with regularization: Theory, Appl. Opt., 38, 2346-2357, doi:10.1364/AO.38.002346, 1999.

Müller, D., Böckmann, C., Kolgotin, A., Schneidenbach, L., Chemyakin, E., Rosemann, J., Znak, P., and Romanov, A.: Microphysical particle properties derived from inversion algorithms developed in the framework of EARLINET, Atmos. Meas. Tech. Discuss., 8, 12823-12885, doi:10.5194/amtd-8-128232015, 2015.

Nair, P. J., Godin-Beekmann, S., Froidevaux, L., Flynn, L. E., Zawodny, J. M., Russell III, J. M., Pazmiño, A., Ancellet, G., Steinbrecht, W., Claude, H., Leblanc, T., McDermid, S., van Gijsel, J. A. E., Johnson, B., Thomas, A., Hubert, D., Lambert, J.-C., Nakane, H., and Swart, D. P. J.: Relative drifts and stability of satellite and ground-based stratospheric ozone profiles at NDACC lidar stations, Atmos. Meas. Tech., 5, 1301-1318, doi:10.5194/amt-5-1301-2012, 2012.

Nemuc, A., Vasilescu, J., Talianu, C., Belegante, L., and Nicolae, D.: Assessment of aerosol's mass concentrations from measured linear particle depolarization ratio (vertically resolved) and simulations, Atmos. Meas. Tech., 6, 3243-3255, doi:10.5194/amt-63243-2013, 2013.
Pappalardo, G., Amodeo, A., Pandolfi, M., Wandinger, U., Ansmann, A., Bösenberg, J., Matthias, V., Amiridis, V., De Tomasi, F., Frioud, M., Iarlori, M., Komguem, L., Papayannis, A., Rocadenbosch, F., and Wang, X.: Aerosol lidar intercomparison in the framework of the EARLINET project. 3. Raman lidar algorithm for aerosol extinction, backscatter and lidar ratio, Appl. Opt., 43, 5370-5385, doi:10.1364/AO.43.005370, 2004.

Pappalardo, G., Amodeo, A., Apituley, A., Comeron, A., Freudenthaler, V., Linné, H., Ansmann, A., Bösenberg, J., D’Amico, G., Mattis, I., Mona, L., Wandinger, U., Amiridis, V., AladosArboledas, L., Nicolae, D., and Wiegner, M.: EARLINET: towards an advanced sustainable European aerosol lidar network, Atmos. Meas. Tech., 7, 2389-2409, doi:10.5194/amt-7-23892014, 2014.

Perrone, M. R., De Tomasi, F., and Gobbi, G. P.: Vertically resolved aerosol properties by multi-wavelength lidar measurements, Atmos. Chem. Phys., 14, 1185-1204, doi:10.5194/acp-14-11852014, 2014.

Rizi, V., Iarlori, M., Rocci, G., and Visconti, G.: Raman lidar observations of cloud liquid water, Appl. Opt., 43, 6440-6453, doi:10.1364/AO.43.006440, 2004.

Schmidt, J., Wandinger, U., and Malinka, A.: Dual-fieldof-view Raman lidar measurements for the retrieval of cloud microphysical properties, Appl. Opt., 52, 2235-2247, doi:10.1364/AO.52.002235, 2013.

Stoyanov, D., Grigorov, I., Kolarov, G., Peshev, Z., and Dreischuh, T.: LIDAR Atmospheric Sensing by Metal Vapor and Nd:YAG Lasers, in Advanced Photonic Sciences, edited by: Fadhali, M., ISBN 978-953-307-927-1, InTech, 2011.

Veselovskii, I., Kolgotin, A., Griaznov, V., Müller, D., Wandinger, U., and Whiteman, D. N.: Inversion with regularization for the retrieval of tropospheric aerosol parameters from multiwavelength lidar sounding, Appl. Opt., 41, 3685-3699, doi:10.1364/AO.41.003685, 2002. 